\title{
Neurochemical Heterogeneity Among Lateral Hypothalamic Hypocretin/Orexin and Melanin- Concentrating Hormone Neurons Identified Through Single-Cell Gene Expression Analysis
}

\author{
Laura E. Mickelsen,, ${ }^{1,}$ Fredrick W. Kolling IV, ${ }^{1,2,}$ Brock R. Chimileski, ${ }^{1}$ Akie Fujita, ${ }^{1,3}$ Carol Norris, ${ }^{2}$ Kun \\ Chen, ${ }^{4}$ Craig E. Nelson, ${ }^{2}$ and ${ }^{(}$Alexander C. Jackson ${ }^{1,5}$
}

\section{DOI:http://dx.doi.org/10.1523/ENEURO.0013-17.2017}

${ }^{1}$ Department of Physiology and Neurobiology, University of Connecticut, Storrs, CT 06269, ${ }^{2}$ Department of Molecular and Cell Biology, University of Connecticut, Storrs, CT 06269, ${ }^{3}$ Department of Biomedical Engineering, University of Connecticut, Storrs, CT 06269, ${ }^{4}$ Department of Statistics, University of Connecticut, Storrs, CT 06269, and

${ }^{5}$ Connecticut Institute for the Brain and Cognitive Sciences, University of Connecticut, Storrs, CT 06269

\begin{abstract}
The lateral hypothalamic area (LHA) lies at the intersection of multiple neural and humoral systems and orchestrates fundamental aspects of behavior. Two neuronal cell types found in the LHA are defined by their expression of hypocretin/orexin (Hcrt/Ox) and melanin-concentrating hormone $(\mathrm{MCH})$ and are both important regulators of arousal, feeding, and metabolism. Conflicting evidence suggests that these cell populations have a more complex signaling repertoire than previously appreciated, particularly in regard to their coexpression of other neuropeptides and the machinery for the synthesis and release of GABA and glutamate. Here, we undertook a single-cell expression profiling approach to decipher the neurochemical phenotype, and heterogeneity therein, of Hcrt/Ox and $\mathrm{MCH}$ neurons. In transgenic mouse lines, we used single-cell quantitative polymerase chain reaction (qPCR) to quantify the expression of 48 key genes, which include neuropeptides, fast neurotransmitter components, and other key markers, which revealed unexpected neurochemical diversity. We found that single $\mathrm{MCH}$ and $\mathrm{Hcrt} / \mathrm{Ox}$ neurons express transcripts for multiple neuropeptides and markers of both excitatory and inhibitory fast neurotransmission. Virtually all $\mathrm{MCH}$ and approximately half of the Hcrt/Ox neurons sampled express both the machinery for glutamate release and GABA synthesis in the absence of a vesicular GABA release pathway. Furthermore, we found that this profile is characteristic of a subpopulation of LHA glutamatergic neurons but contrasts with a broad population of LHA GABAergic neurons. Identifying the neurochemical diversity of Hcrt/Ox and $\mathrm{MCH}$ neurons will further our understanding of how these populations modulate postsynaptic excitability through multiple signaling mechanisms and coordinate diverse behavioral outputs.
\end{abstract}

Key words: cotransmission; hypocretin/orexin; lateral hypothalamic area; melanin-concentrating hormone; neuropeptide; neurotransmitter

\section{Significance Statement}

The lateral hypothalamic area (LHA) is a key regulator of fundamental behavioral states such as arousal, stress, and reward, and disruption of neural circuits in this region is associated with disorders of sleep, feeding, and motivated behavior. The multifunctional nature of the LHA is attributable to a heterogeneous population of neurons that exhibit significant phenotypic and neurochemical diversity. Here, we sought to resolve aspects of this diversity in two well-studied but incompletely understood LHA neuron populations, defined by their expression of neuropeptides hypocretin/orexin (Hcrt/Ox) and melanin-concentrating hormone (MCH). These efforts lay a foundation for understanding, at a molecular and cellular level, how Hcrt/Ox and $\mathrm{MCH}$ neurons coordinate behavioral output and thereby give rise to fundamental innate behavioral states. 


\section{Introduction}

The lateral hypothalamic area (LHA) is a powerful modulator of behavioral state through its ability to integrate diverse central and peripheral signals and orchestrate adaptive responses to challenges in the environment. Such functions include the organization of sleep-wake states, feeding, energy balance, and motivated behavior (Berthoud and Münzberg, 2011; Burdakov et al., 2013; Hurley and Johnson, 2014; Brown et al., 2015; Bonnavion et al., 2016; Herrera et al., 2016; Stuber and Wise, 2016), the dysregulation of which are cardinal symptoms of both neuropsychiatric illnesses and metabolic disorders (Wulff et al., 2010; Spiegelhalder et al., 2013; Liu et al., 2014). The LHA thus plays a vital role in coordinating physiologic and behavioral homeostasis to ensure survival (Sternson, 2013).

Underlying the diverse functions of the LHA is a heterogeneous population of neurons, of which only a few have been definitively identified and characterized. Hypocretin/ orexin (Hcrt/Ox) and melanin-concentrating hormone $(\mathrm{MCH})$ neurons make up two neuropeptidergic neuronal populations which, despite comprising a relatively small proportion of cells within the LHA, have a profound impact on brain function. Both populations regulate sleep-wake states, but have also been implicated in feeding, metabolism, stress and reward-related behaviors (Burt et al., 2011; Barson et al., 2013; Jones and Hassani, 2013; Brown et al., 2015; Konadhode et al., 2015; Bonnavion et al., 2016; Herrera et al., 2016; Stuber and Wise, 2016)

Hcrt/Ox neurons project widely, serve as key integrators of a diverse set of inputs from both the CNS and periphery, and exert homeostatic control over arousal, feeding, reward and stress. Furthermore, Hcrt/Ox signaling has been implicated in the stabilization of sleep-wake states and its dysfunction has been directly linked to narcolepsy in animal models and humans (Alexandre et al., 2013; Giardino and de Lecea, 2014; Mahler et al., 2014; Sakurai, 2014). Importantly, the electrical activity of

Received January 11, 2017; accepted August 25, 2017; First published September 1, 2017

The authors declare no competing financial interests.

Author contributions: L.E.M, F.W.K., C.E.N. and A.C.J. designed research; L.E.M., F.W.K., B.R.C., A.F., C.N. and A.C.J. performed research; L.E.M, F.W.K., B.R.C., A.F., K.C. and A.C.J. analyzed data; L.E.M., F.W.K. and A.C.J. wrote the paper.

This work was supported by a K99/R00 (R00MH097792) and an R01 (R01MH112739) from the National Institute of Mental Health (to A.C.J.) and the National Institutes of Health Shared Instrumentation Grant S100D016435 (PI: Dr. Akiko Nishiyama) for imaging support.

*L.E.M. and F.W.K. contributed equally to this work

Acknowledgements: We thank Dr. Takeshi Sakurai for use of the Ox-EGFP transgenic mouse line, Dr. Siu-Pok Yee for transgenic mouse rederivation, and Kristen Springer for mouse genotyping. We also thank Dr. Barbara Jones, Dr. Luis de Lecea, Dr. Rahul Kanadia, Dr. Akiko Nishiyama and Dr. Anna Lisa Lucido for valuable discussions and comments on this manuscript.

Correspondence should be addressed to Alexander C. Jackson. Dept. Physiology and Neurobiology, University of Connecticut, Storrs, CT 06269. E-mail: alexander.jackson@uconn.edu.

DOI:http://dx.doi.org/10.1523/ENEURO.0013-17.2017

Copyright (C) 2017 Mickelsen et al.

This is an open-access article distributed under the terms of the Creative Commons Attribution 4.0 International license, which permits unrestricted use, distribution and reproduction in any medium provided that the original work is properly attributed.
Hcrt/Ox neurons is directly correlated with behavioral state, firing at high frequencies during high arousal states and at low frequencies or not at all during low arousal states and sleep (Lee, 2005; Mileykovskiy et al., 2005; Takahashi et al., 2008; Hassani et al., 2009, 2016; González et al., 2016). MCH neurons, in turn, are also unique to the LHA and are implicated in regulating sleepwake states, as well as feeding and metabolism (Pissios et al., 2006; Monti et al., 2013). Optogenetic experiments show that, whereas activation of Hcrt/Ox neurons promotes wakefulness and behavioral arousal, stimulation of $\mathrm{MCH}$ neurons promotes sleep (Adamantidis et al., 2007; Jego et al., 2013; Konadhode et al., 2013; Tsunematsu et al., 2014; Blanco-Centurion et al., 2016; Vetrivelan et al., 2016).

Despite the crucial role of these neurons in maintaining behavioral homeostasis, outstanding questions remain concerning the neurochemical diversity of Hcrt/Ox and $\mathrm{MCH}$ neurons, particularly in regard to their coexpression of other neuropeptides and necessary components for the synthesis and release of the fast amino acid neurotransmitters GABA and glutamate. Anatomic data reveal that both populations may be neurochemically heterogeneous in terms of their neuropeptide coexpression and markers for one or more fast neurotransmitters, including machinery for GABA synthesis (GAD65/67), vesicular GABA release (VGAT) and vesicular glutamate release (VGLUT1, VGLUT2, or VGLUT3; Brown et al., 2015; Bonnavion et al., 2016; Stuber and Wise, 2016). A systematic assessment of the neurochemical phenotype of Hcrt/Ox and $\mathrm{MCH}$ neurons is lacking owing to the challenge of profiling the expression of many genes in cleanly isolated neurons, which are scattered throughout the LHA and intermingled with other cell populations. Here, we optimized a robust procedure for isolating single, transgenically-labeled $\mathrm{Hcrt} / \mathrm{Ox}$ and $\mathrm{MCH}$ neurons and employed a single-cell quantitative polymerase chain reaction (qPCR) profiling approach to discern their expression of a panel of 48 key genes that encode neuropeptides, fast neurotransmitter components and other key markers. The goal of our study is, through a single-cell gene expression profiling approach, to more fully resolve the neurochemical profile of $\mathrm{Hcrt} / \mathrm{Ox}$ and $\mathrm{MCH}$ neurons, which would shed light on the full extent of their signaling repertoire at postsynaptic targets and inform their role in driving complex, innate behavior.

\section{Materials and Methods}

\section{Ethics statement}

All experiments were performed in accordance with the guidelines described in the National Institutes of Health Guide for the Care and Use of Laboratory Animals and were approved by the Institutional Animal Care and Use Committee of the University of Connecticut.

\section{Animals}

Transgenic mice used to identify Hcrt/Ox neurons expressed enhanced green fluorescent protein (EGFP), under the control of the human prepro-orexin promoter (Sakurai et al., 1999; Yamanaka et al., 2003), referred to here as Ox-EGFP. To identify $\mathrm{MCH}$ neurons, we used 


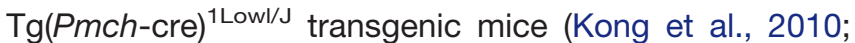
JAX stock 014099, RRID: IMSR_JAX:01499), which was crossed to an enhanced yellow fluorescent protein (EYFP) reporter line, B6.Cg-Gt(ROSA)26Sor ${ }^{\text {tm3(CAG-EYFP)Hze } / J ~}$ (Ai3; Madisen et al., 2010; JAX stock 007903, RRID: IMSR_JAX:007903), which selectively expresses EYFP following cre-dependent recombination. The resulting cross is referred to here as Pmch-Cre;EYFP. We also used

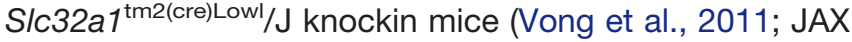
stock 016962, RRID: IMSR_JAX:016962) to label VGATexpressing GABAergic neurons and S/c17a6 $6^{\mathrm{tm} 2(\text { cre)Lowl } / J}$ knockin mice (Vong et al., 2011; JAX stock 016963, RRID: IMSR_JAX:016963) to label S/c17a6-expressing glutamatergic neurons. Each of these lines were similarly crossed to Ai3 and referred to here as Vgat-Cre;EYFP and Vglut2Cre;EYFP, respectively. Wild type mice used for neuroanatomical analysis were C57BL/6 (JAX stock 000664, RRID: IMSR_JAX:000664). All mice were fed ad libitum and kept on a 12/12 h light/dark cycle.

\section{Brain slice preparation for microdissection and single-cell dissociation}

Hypothalamic brain slices through the LHA were taken from five Ox-EGFP, 5 Pmch-Cre;EYFP, 2 Vgat-Cre;EYFP and two Vglut2-Cre;EYFP male juvenile mice (postnatal days P21-P23). Brain slice preparation was conducted between 9 and 11 A.M. for the described experiments. Following anesthesia with isofluorane, 225- $\mu \mathrm{m}$-thick slices were prepared using a vibrating microtome (Campden Instruments model 7000smz-2) in ice-cold, sucrose slicing solution containing $87 \mathrm{mM} \mathrm{NaCl}, 75 \mathrm{mM}$ sucrose, $25 \mathrm{mM}$ glucose, $25 \mathrm{mM} \mathrm{NaHCO}_{3}, 1.25 \mathrm{mM} \mathrm{NaH}_{2} \mathrm{PO}_{4}, 2.5$ $\mathrm{mM} \mathrm{KCl}, 7.5 \mathrm{mM} \mathrm{MgCl}, 0.5 \mathrm{mM} \mathrm{CaCl}_{2}$, and $5 \mathrm{mM}$ ascorbic acid saturated with $95 \% \quad \mathrm{CO}_{2} / 5 \% \quad \mathrm{O}_{2}$. Slices were enzyme-treated for $\sim 15 \mathrm{~min}$ at $34^{\circ} \mathrm{C}$ using protease XXIII $(2.5 \mathrm{mg} / \mathrm{ml}$; Sigma) in a sucrose dissociation solution containing $185 \mathrm{mM}$ sucrose, $10 \mathrm{mM}$ glucose, $30 \mathrm{mM}$ $\mathrm{Na}_{2} \mathrm{SO}_{4}, 2 \mathrm{mM} \mathrm{K}_{2} \mathrm{SO}_{4}, 10 \mathrm{mM}$ HEPES, $0.5 \mathrm{mM} \mathrm{CaCl}_{2} 6$ $\mathrm{mM} \mathrm{MgCl}$, and $5 \mathrm{mM}$ ascorbic acid, $\mathrm{pH}$ 7.4, 320 mOsm. Slices were washed three times with cold dissociation solution then transferred to trypsin inhibitor/bovine serum albumin (BSA; $1 \mathrm{mg} / \mathrm{ml}$; Sigma) in cold sucrose dissociation solution. Typically, three slices were obtained from each animal, that approximately corresponded to mouse brain atlas images representing bregma $-1.24,-1.58$, and $-1.82 \mathrm{~mm}$ (Paxinos and Franklin, 2012), which encompassed the region of the LHA caudal to the level of the retrochiasmatic area and rostral to the level of the tuberomammillary nucleus in the posterior hypothalamus. The LHA was microdissected bilaterally from appropriate slices using a $1.0 \mathrm{~mm}$ diameter disposable biopsy punch (Ted Pella). Under a dissecting microscope, the tissue punch was placed to optimally excise the region of the LHA from each slice, based on visual identification of key anatomic landmarks: ventral to the mammillothalamic tract (mt), medioventral to the cerebral peduncle (cp), lateral to the dorsomedial nucleus of the hypothalamus, dorsolateral to the ventromedial nucleus of the hypothalamus, and including the fornix in the medioventral quadrant of each punch. Each microdissected brain slice was then photographed and the borders of the tissue punch were subsequently mapped onto mouse brain atlas images (Paxinos and Franklin, 2012). Microdissected tissue punches were kept in sucrose dissociation solution (with trypsin inhibitor/BSA) on ice until trituration. Immediately before dissociation, tissue punches were incubated for $\sim 10$ min in a $37^{\circ} \mathrm{C}$ water bath, then triturated with a series of small bore fire-polished glass Pasteur pipettes in a volume of 400-600 $\mu \mathrm{l}$ trypsin inhibitor/BSA sucrose dissociation solution. Single-cell suspensions were passed through $60 \mu \mathrm{m}$ nylon mesh filters to remove any cell aggregates, and kept on ice until fluorescence-activated cell sorting (FACS). to obtain sufficient number of cells for FACS, punches from multiple animals were pooled together for each FACS collection. Ox-EGFP and PmchCre;EYFP mice were FACS sorted in two collections each (two to three mice per collection) while Vgat-Cre;EYFP and Vglut2-Cre;EYFP were sorted in single collections (two mice per collection).

\section{Fluorescence-activated cell sorting (FACS)}

EGFP+ or EYFP+ neurons were sorted on a BD FACSAria II Cell Sorter (UConn Flow Cytometry Facility, Storrs CT, RRID: SCR_012341) equipped with a sapphire $488 \mathrm{~nm}$ excitation laser (Coherent). Cells were selected based on scatter and for singlets, then gated on the presence of EGFP/EYFP fluorescence (PE-A vs GFP-A) and sorted in single-cell precision mode with a $10 \mathrm{~K}$ threshold into a sterile 96 -well plate containing $2.5 \mu \mathrm{l}$ lysis buffer [0.5\% NP-40, $1 \mathrm{U} / \mu \mathrm{l}$ RNAsin + (Promega), 0.25× pooled TaqMan assays], snap frozen on dry ice, and stored at $-80^{\circ} \mathrm{C}$ until processing for single-cell qPCR. To control for free-RNA contamination in FACS-sorted droplets, calibrite allophycocyanin (APC) beads (Beckton Dickenson) were added to all LHA single-cell suspensions and single beads were sorted based on red/orange fluorescence via FACS using the same gating parameters as single-cells. Beads were snap frozen and underwent qPCR alongside single cells. In initial experiments, single EGFP + cells were FACS-sorted using the same gating parameters into flat-bottomed wells of a Terasaki plate (Yaron et al., 2014; Tasic et al., 2016) containing $5 \mu \mathrm{l}$ of 10 $\mathrm{mg} / \mathrm{ml}$ trypsin inhibitor/BSA in dissociation sucrose and visualized under a fluorescence microscope.

\section{Single-cell qPCR}

Plates of FACS-sorted cells were thawed and a combined lysis/denaturation step was performed by incubation at $70^{\circ} \mathrm{C} / 4 \mathrm{~min}, 4^{\circ} \mathrm{C} / 5 \mathrm{~min}, 2.5 \mu \mathrm{l}$ reverse transcription master mix was then added to each well $[1 \mu \mathrm{l} 5 \times \mathrm{RT}$ buffer (Promega), $0.6 \mu \mathrm{l} 35 \mathrm{mM} \mathrm{MgCl}, 0.25 \mu$ l Moloney murine leukemia virus (Promega), $0.1 \mu \mathrm{l} 25 \mathrm{mM}$ dNTPs, $0.5 \mu \mathrm{l} \mathrm{H}_{2} \mathrm{O}$ ] and incubated at $37^{\circ} \mathrm{C} / 2 \mathrm{~min}, 42^{\circ} \mathrm{C} / 1 \mathrm{~min}$, $50^{\circ} \mathrm{C} / 1 \mathrm{~s}$ for 40 cycles, then $85^{\circ} \mathrm{C} / 5 \mathrm{~min}$, and $4^{\circ} \mathrm{C}$ hold. Following RT, cDNA was preamplified by adding $2 \mu \mathrm{l}$ of cDNA from the RT plate to $8 \mu$ l of preamp master mix [5 $\mu \mathrm{l}$ TaKaRa premix Taq polymerase (Clontech), $2.5 \mu \mathrm{l}$ 0.25X TaqMan pool, $0.5 \mu \mathrm{l} \mathrm{H}_{2} \mathrm{O}$ ] and thermocycled at $95^{\circ} \mathrm{C} / 3 \mathrm{~min}, 55^{\circ} \mathrm{C} / 2 \mathrm{~min}, 72^{\circ} \mathrm{C} / 2 \mathrm{~min}$, then $95^{\circ} \mathrm{C} / 15 \mathrm{~s}$, $60^{\circ} \mathrm{C} / 2 \mathrm{~min}, 72^{\circ} \mathrm{C} / 2$ min for 16 cycles, and $4^{\circ} \mathrm{C}$ hold. Amplified cDNA was then diluted 1:50 in nuclease-free 
$\mathrm{H}_{2} \mathrm{O}$ and this material was used for qPCR against a curated panel of 48 TaqMan Gene Expression Assays (Table 1) on 48.48 dynamic arrays using a Biomark HD system (Fluidigm).

\section{QPCR data analysis}

Raw cycle threshold (Ct) values were obtained from the Fluidigm Biomark software and inverted (35-Ct) to generate a $\log _{2}$-based scale for gene expression analysis. To eliminate cells with low/no cDNA yield, we filtered our dataset to include only cells within the $95 \%$ confidence interval (Cl) for Gapdh expression after removing cells absent for the transcript. Hierarchical clustering was performed using Ward's method with complete linkage (Ward, 1963). For principle component analysis (PCA), gene expression was $z$ score normalized and processed using the princomp function in R. To examine potential subclusters and/or batch effects, we used both multiple hypothesis testing analysis using custom routines and the fisher.test function in R as well as PCA analysis using the princomp function in R. To quantitatively compare gene expression between Hcrt/Ox and $\mathrm{MCH}$ neurons, we performed multiple hypothesis testing on the 48 genes using Fisher's exact test (Agresti, 1992) to report adjusted $p$ values, with the Benjamini-Hochberg procedure (Benjamini and Hochberg, 1995) to control the false discovery rate (FDR) at $5 \%$. All statistical analyses were performed using R (The R Project for Statistical Computing; www.rproject.org, RRID: SCR_001905).

\section{Statistical power analysis}

We performed power analysis to assess whether the numbers of neurons used in this study are adequate to achieve sufficient statistical power in detecting differential gene expression. To this end, we used a simulation in which the sample sizes are fixed at the same values of the real data (Hcrt/Ox: 69; MCH: 89), and the true difference between the two probabilities of expression is set to various levels $(0 \%, 15 \%, 25 \%$, and $35 \%)$. With each simulation, presence/absence data are randomly generated, for which the Fisher's exact test (Agresti, 1992) was performed at $5 \%$ significance level. The simulations were repeated 1000 times under each setting of true probabilities and effect size, and the proportion of times that the test is rejected is then an estimate of the corresponding power. Power analysis via simulation was performed using custom routines in $\mathrm{R}$.

\section{Fluorescence in situ hybridization (FISH)}

To prepare tissue sections for FISH, male juvenile (postnatal days P21-P24) wild type C57BL/6 mice were anesthetized with isoflurane, decapitated, and brains were dissected out into ice-cold sucrose. Brains were rapidly frozen on dry ice, embedded in OCT compound and cryosectioned at a thickness of $14 \mu \mathrm{m}$ onto SuperFrost Plus microscope slides. Sections were fixed with $4 \%$ paraformaldehyde (PFA) at $4^{\circ} \mathrm{C}$ for $15 \mathrm{~min}$, and then dehydrated in $50 \%, 70 \%$, and $100 \%$ ethanol. RNAscope 2.5 Assay (Advanced Cell Diagnostics, ACD, RRID: SCR_012481) was used for all FISH experiments according to manufacturer's protocols (Wang et al., 2012). All
RNAscope FISH probes were designed and validated by ACD.

\section{Imaging and image quantification of FISH data}

Confocal images of FISH experiments were obtained using a Leica TSC Sp8 and confocal image files (lif) containing image stacks were loaded into ImageJ (version 2.0.0, NIH, RRID: SCR_003070) and processed to analyze percentage colocalization between mRNA transcripts for various neuropeptide or neurotransmitter components and Hcrt or Pmch. Cells were marked and categorized using the ImageJ cell counter plugin. Cells showing expression in the orange (TRITC) channel for one of the following mRNA: Cartpt, Nucb2, Pdyn, Penk, Gad1, Slc32a1, or Slc17a6 were counted and marked. Expression was denoted as binary yes/no dependent on the fulfillment of a defined criteria; the presence of at least five punctate fluorescent dots accompanying a nucleus labeled by 4',6-diamidino-2-phenylindole (DAPI; Vector Laboratories, RRID: AB_2336788). Subsequently, cells showing expression in the green (FITC) channel (for either Hcrt or Pmch) were similarly marked. Cells that were double marked through this process were identified as cells exhibiting colocalization. This process was repeated for multiple lif files for each FISH experiment, and the total number of colocalized cells versus the total number of Hcrt- or Pmch-expressing cells was used to create pie charts displaying percentage colocalization, where $\mathrm{n}$ values describe the total number of Hcrt- or Pmchexpressing cells analyzed.

\section{Immunohistochemistry (IHC)}

For IHC analysis, male C57BL/6, Ox-EGFP and PmchCre;EYFP mice were transcardially perfused with $10 \mathrm{ml}$ $0.125 \mathrm{M} \mathrm{NaCl}$, then $40 \mathrm{ml}$ of a $1 \times$ PBS solution $(\mathrm{pH} \mathrm{7.4)}$ containing 4\% PFA. Brains were postfixed overnight, then cryoprotected in $30 \%$ sucrose for $48 \mathrm{~h}$ before being frozen in cold isopentane and stored at $-80^{\circ} \mathrm{C}$. Frozen brains were cut in coronal sections, $40 \mu \mathrm{m}$ thick, on a cryostat (Leica CM 3050s). Sections were washed $3 \times 5$ min in $1 \times$ PBS, then washed $3 \times 5$ min in PBS supplemented with $0.2 \%$ Tween 20 (PBST). Slices were incubated in a blocking solution containing PBST supplemented with $2 \%$ donkey normal serum for $2 \mathrm{~h}$ at room temperature (RT). Slices were then incubated with goat anti-orexin A (1:1000, Santa Cruz Biotechnology, catalog SC-8070, RRID: AB_653610), rabbit anti-MCH (1:1000, Phoenix Pharmaceuticals, H-070-47, RRID: AB_10013632), rabbit anti-CART (1:1000, Phoenix Pharmaceuticals, H-003-61), rabbit anti-nesfatin-1 (NUCB2; 1:1000, Phoenix Pharmaceuticals, H-003-22, RRID: AB_2313672), or mouse anti-GFP (ThermoFisher Scientific, A-11120, RRID: AB_221568). After multiple washes in PBST, the sections were then incubated with appropriate secondary antibody raised in donkey for either Alexa Fluor 488 or Alexa Fluor 594 (1:500, Abcam) in blocking solution for $2 \mathrm{~h}$ at RT. Sections were washed $5 \times$ $10 \mathrm{~min}$ in PBST and $5 \times 10 \mathrm{~min}$ in PBS, then mounted onto slides and cover-slipped with Vectashield hardset mounting media with DAPI (Vector Laboratories). Fluorescence images were obtained using a Zeiss Imager M2 (Carl Zeiss Microlmaging) with an Orca-R2 digital CCD camera (Hama- 
matsu Photonics). Confocal images were obtained using a Leica TSC Sp8. Images were processed using Image $(\mathrm{NIH})$, Photoshop CS (Adobe, RRID: SCR_014199), and Adobe Illustrator CC (Adobe, RRID: SCR_010279) and cell counting was performed on confocal micrographs.

\section{Brain slice preparation for patch-clamp recording and manual harvest}

Coronal brain slices containing the LHA were prepared from male juvenile (P21-P23) Ox-EGFP and Pmch-Cre; EYFP mice. Mice were deeply anesthetized with ketamine/xylazine before being transcardially perfused with ice-cold high-sucrose cutting solution before slicing using a vibrating microtome as described previously. Hypothalamic slices containing the LHA (225 $\mu \mathrm{m}$ thick) were then placed in a recovery chamber containing artificial CSF (ACSF) consisting of $125 \mathrm{mM} \mathrm{NaCl}, 2.5 \mathrm{mM} \mathrm{KCl}, 25 \mathrm{mM}$ $\mathrm{NaHCO}_{3}, 1.25 \mathrm{mM} \mathrm{Na}_{2} \mathrm{PO}_{4}, 25 \mathrm{mM}$ glucose, $2 \mathrm{mM} \mathrm{CaCl}_{2}$, and $1 \mathrm{mM} \mathrm{MgCl} 2$, saturated with $95 \% \mathrm{O}_{2} / 5 \% \mathrm{CO}_{2}$, and allowed to recover for $45 \mathrm{~min}$ at $34-35^{\circ} \mathrm{C}$ and at least 30 min at RT before recording. Cells were visualized with an upright Olympus BX51 microscope (Olympus America) with infrared differential interference contrast and identified by EGFP expression with epifluorescence illumination. The slice in the recording chamber was superfused with bubbled ACSF at physiological temperature (34$35^{\circ} \mathrm{C}$ ), at which all recordings were performed. All recordings were acquired using a Multiclamp 700B amplifier (Molecular Devices). Whole-cell patch-clamp recordings from EGFP + Hcrt/Ox neurons were conducted using thinwalled borosilicate glass pipettes (World Precision Instruments) with $R_{\text {pipette }}$ values of 2-6 $M \Omega$. Pipettes were backfilled with $1 \mu \mathrm{l}$ RNase-free internal solution containing $130 \mathrm{mM} \mathrm{K}$-gluconate, $10 \mathrm{mM}$ HEPES, $0.1 \mathrm{mM}$ EGTA, $10 \mathrm{mM} \mathrm{NaCl}$, and $2 \mathrm{mM} \mathrm{MgCl}$ with $20 \mu \mathrm{g} / \mathrm{ml}$ glycogen and $1 \mathrm{U} / \mu \mathrm{l}$ RNase inhibitor made with RNase-free $\mathrm{H}_{2} \mathrm{O}$. All recordings were conducted using a Multiclamp $700 \mathrm{~B}$ amplifier (Molecular Devices), digitized at $10 \mathrm{kHz}$ and filtered at $2 \mathrm{kHz}$ using a Digidata 1440 digitizer (Molecular Devices) and were acquired using pClamp10 software (Molecular Devices, RRID:SCR_011323). Data were analyzed using ClampFit (Molecular Devices) and custom procedures in IgorPro (Wavemetrics, RRID: SCR_00325). Only cells with an $R_{\text {access }}$ below $15 \mathrm{M} \Omega$ were accepted. In current-clamp mode, neurons were subjected to hyperpolarizing and depolarizing step pulses $( \pm 40 \mathrm{pA})$. RNA was collected at the end of recording (typically 3-5 min after initial break-in) by applying light suction until the cell cytoplasm had been aspirated (Citri et al., 2011; Cadwell et al., 2015; Fuzik et al., 2015). The contents of the pipette were expelled using positive pressure into an RNase free PCR tube containing lysis buffer (described above), snap frozen on dry ice and stored at $-80^{\circ} \mathrm{C}$ until further processing for single-cell qPCR.

\section{Results}

\section{Immunohistochemical validation of Ox-EGFP and Pmch-Cre;EYFP transgenic mice}

To identify labeled Hcrt/Ox and $\mathrm{MCH}$ neurons for FACS and for recording in brain slices, we used Ox-EGFP and

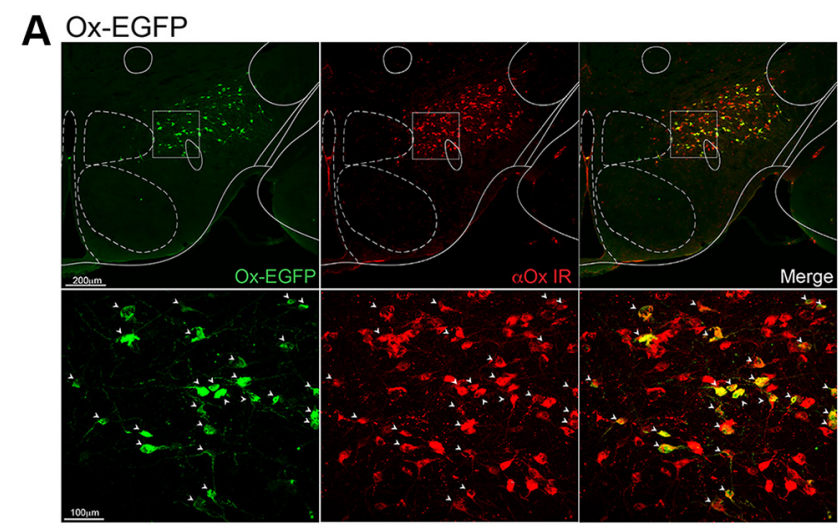

B Pmch-Cre;EYFP

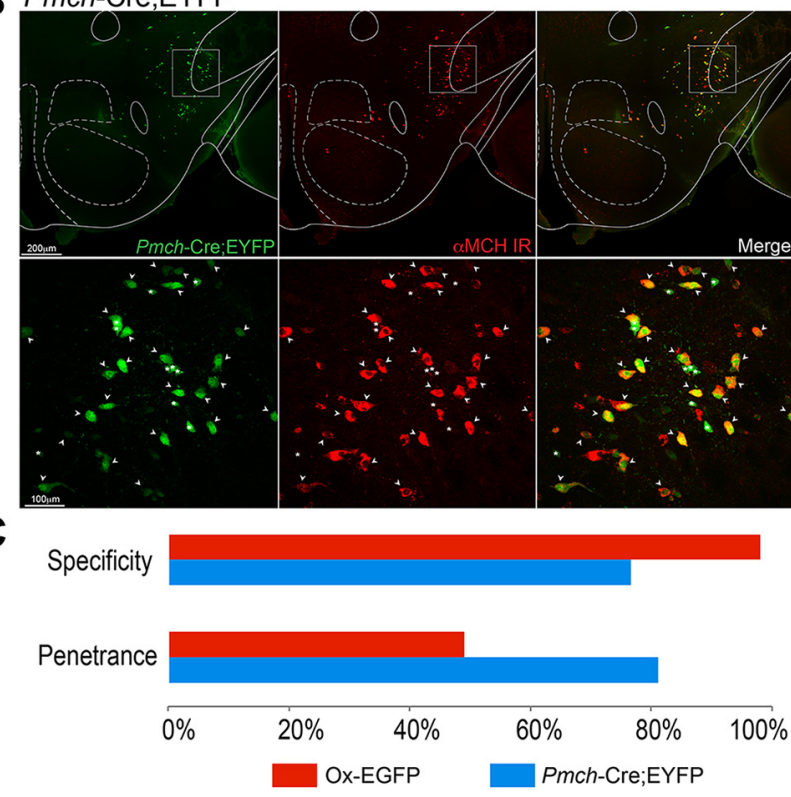

Figure 1. Characterization of Ox-EGFP and Pmch-Cre;EYFP mouse lines. A, Fluorescent micrographs (top) of coronal sections of Ox-EGFP mouse brains counterstained for anti-OxA and confocal micrographs of the boxed region (bottom). White arrows indicate co-localization. $\boldsymbol{B}$, Fluorescent micrographs (top) of coronal sections of Pmch-Cre;EYFP mouse brains counterstained for anti-MCH and corresponding confocal micrographs (bottom). White arrows indicate co-localization. C, Bar graph representing specificity and penetrance of Ox-EGFP mice (red, $n=3$ ) and Pmch-Cre;EYFP (blue, $n=3$ ).

Pmch-Cre;EYFP mice. In both cases, we quantitatively evaluated the fidelity with which each transgenic mouse line expresses EGFP or EYFP in Hcrt/Ox and $\mathrm{MCH}$ neurons, respectively, through IHC. To assess specificity of Ox-EGFP mice, we quantified the number of EGFP + cells which were Hcrt/Ox-immunoreactive (IR) and found the specificity to be $\sim 98 \%$ ( $n=3$ mice). To assess penetrance, we quantified the number of Hcrt/Ox-IR cells that were EGFP + and found the penetrance to be $\sim 49 \%$ (Fig. 1C). We performed a similar analysis using Pmch-Cre; EYFP mice (Fig. 1B) and found the specificity of this transgenic line to be $\sim 77 \%$ and the penetrance to be $\sim 81 \%$ ( $n=3$ mice; Fig. $1 C$ ). Thus, we found the Ox-EGFP transgenic mouse to label Hcrt/Ox neurons with high specificity but relatively low penetrance, broadly consis- 
tent with the description of the specificity and penetrance of previously described Ox-nLacZ transgenic mice that share the same promoter (Sakurai et al., 1999). In turn, Pmch-Cre;EYFP mice were effective in selectively labeling Pmch-expressing neurons with reasonably high specificity and penetrance. Although we found penetrance to be in line with the original description of this mouse line (Kong et al., 2010), specificity was less than described. We used both transgenic lines in our subsequent singlecell gene expression profiling and electrophysiological analysis.

\section{Precise and reproducible microdissection and FACS of Hcrt/Ox and $\mathrm{MCH}$ neurons from brain slices}

To isolate and capture Hcrt/Ox and $\mathrm{MCH}$ neurons for single-cell expression profiling, we optimized a method for the precise and reproducible microdissection of the LHA from coronal brain slices from juvenile mice (P21P23) and subsequent isolation of single neurons for qPCR via FACS (Fig. 2A). In our microdissection, we used a 1 $\mathrm{mm}$ diameter circular tissue punch to dissect the LHA from 225- $\mu \mathrm{m}$-thick coronal brain slices containing the LHA from Ox-EGFP and Pmch-Cre;EYFP mice. Following enzyme treatment of whole brain slices, the LHA was visually identified under a dissecting microscope using anatomic landmarks. In all cases, bilateral tissue punches from each slice were subsequently imaged and transposed onto a schematic representation of each of the three representative atlas images to record the accuracy and reproducibility of each microdissection (Fig. 2B,C). To ensure accuracy of the microdissection in capturing the highest concentration of labeled Hcrt/Ox (Fig. 2B) and $\mathrm{MCH}$ (Fig. 2C) neurons, representative tissue punches were mounted and imaged. Finally, the tissue punches from each preparation were triturated to yield suspensions of healthy LHA neurons with intact fluorescence, shown in representative images (Fig. 2B,C).

Following gentle trituration and a filtration step to remove aggregates, single-cell suspensions were loaded onto a BD FACSAria II Cell Sorter. To remove debris and minimize the chance of collecting more than a single EGFP + neuron, a 10K threshold was applied to maximally filter debris in the media. Cells were selected based on scatter, and for singlets, gated on the presence of EGFP/ EYFP fluorescence (PE-A vs GFP-A) and sorted into 96-well PCR plates in single-cell purity mode. A representative FACS run, sorting Ox-EGFP neurons under the described conditions, is shown (Fig. 2D). To further test the reliability of our FACS configuration to sort only a single EGFP + neuron in each well, we performed control experiments in which we visualized sorted single cells in 72-well Terasaki plates. As shown in a representative example (Fig. 2E), the flat, optically clear bottoms of the wells of Terasaki plates allowed us to visualize the entire field of each well. In initial experiments using Ox-EGFP neurons, we observed only single EGFP + neurons in each well and failed to detect doublets or any visible debris. Using this method, we were able to successfully sort intact, single EGFP+ or EYFP+ neurons into each well with minimal debris. Further controls for potential contamination were conducted in our subsequent qPCR analysis.

\section{Panel of 48 key genes used in qPCR analysis of $\mathrm{Hcrt} / \mathrm{Ox}$ and $\mathrm{MCH}$ neurons}

To characterize the neurochemical phenotypes of $\mathrm{Hcrt} / \mathrm{Ox}$ and $\mathrm{MCH}$ neurons, we subjected FACS-purified, single Ox-EGFP and Pmch-Cre;EYFP neurons to qPCR analysis of the expression of 48 key genes. For this purpose, we used TaqMan Gene Expression Assays on 48.48 dynamic arrays using a microfluidic Biomark HD system (Fluidigm). We developed a custom, curated gene panel (Table 1) comprising a wide variety of genes associated with neuronal function and neurochemical phenotype, selected for their potential ability to serve as positive and negative controls for distinct LHA cell populations based on previous molecular and anatomic characterization. These include housekeeping genes (Gapdh and Hprt), neuronal markers (Rbfox3, Map2, and Tubb3) and glial markers (Gfap and S100b) to ensure the analysis of intact, single neurons with minimal glial contamination. We included key neuropeptides known to be expressed in the LHA (Hcrt, Pmch, Pdyn, Gal, Nts, Cartpt, etc.) in addition to others which have not been clearly described in the LHA. Markers of fast amino acid neurotransmission were represented including genes necessary for GABA synthesis (Gad1 and Gad2) and vesicular GABA transport (S/c32a1) as well as glutamate vesicular transport (S/c17a7, S/c17a6, and S/c17a8) and metabolism (G/s). Genes associated with cholinergic and monoaminergic synthesis and release were also included (Chat, Th, Hdc, $T p h, S / c 18 a 2$, etc.) to largely serve as negative controls given the relative dearth of such cell populations in the LHA (Abrahamson and Moore, 2001; Lein et al., 2007). Calcium-binding proteins have shown cell type-specific expression in many other brain regions (Hof et al., 1999), and a Pvalb-expressing population of glutamatergic neurons in the LHA has been described (Mészár et al., 2012) and were thus also included (Pvalb, Calb2, and Calb1). Several key transcription factors are known to be relatively specific for LHA cell types, such as $N k \times 2.1$ for $\mathrm{MCH}$ neurons (Croizier et al., 2011) and Lhx9 for Hcrt/Ox neurons (Shimogori et al., 2010; Dalal et al., 2013; Liu et al., 2015; Sokolowski et al., 2015), and thus serve as important positive controls. To validate findings from previous work (Reti et al., 2002; Crocker et al., 2005; Honda et al., 2009; Shimogori et al., 2010; Dalal et al., 2013; Liu et al., 2015; Sokolowski et al., 2015), we included a number of genes known to be robustly expressed in Hcrt/Ox neurons (Nptx2, Igbp3, Celf6, and Nnat), as well as three key receptor genes (Lepr, Ghsr, and Mc4r), implicated in LHA function. Two of these (Lepr and Mc4r) have been shown to be expressed in overlapping populations of LHA neurons, separate from Hcrt/Ox and $\mathrm{MCH}$ neurons (Leinninger et al., 2009; Cui et al., 2012). To ensure only intact neurons with robust gene expression were used for our analysis, all cells collected by FACS were prescreened for the expression of Gapdh and outliers $(\mathrm{Cl}=95 \%)$ were removed, resulting in a total of 89 Pmch-Cre;EYFP and 70 
A
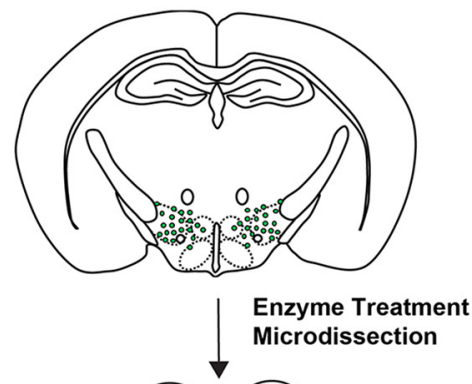

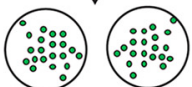
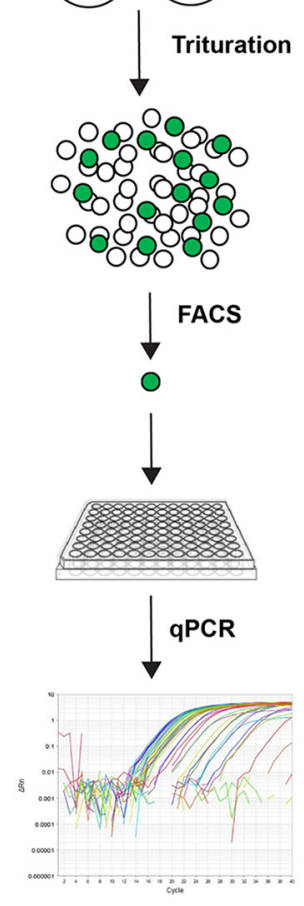

B

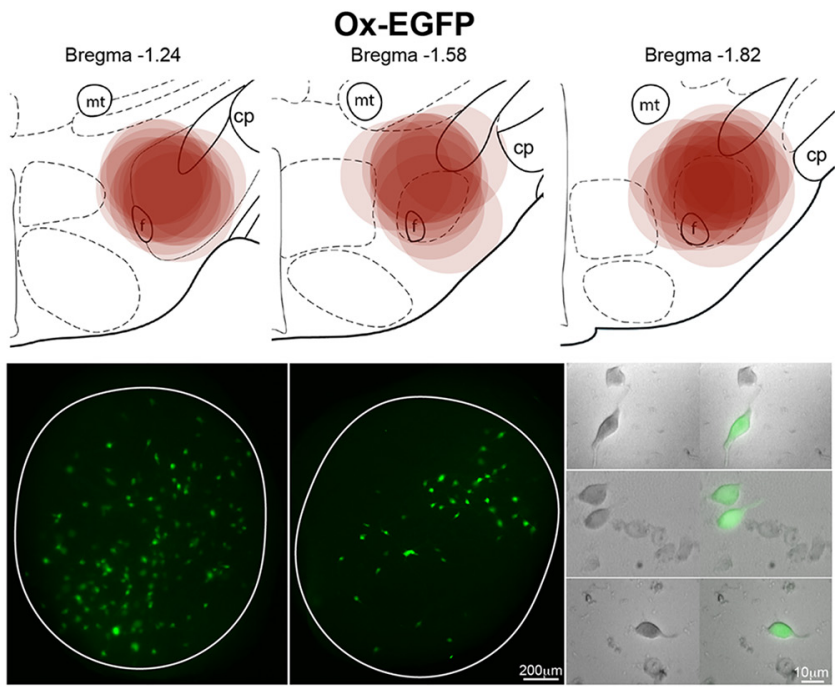

C

Pmch-Cre;EYFP

Bregma -1.24

Bregma -1.58
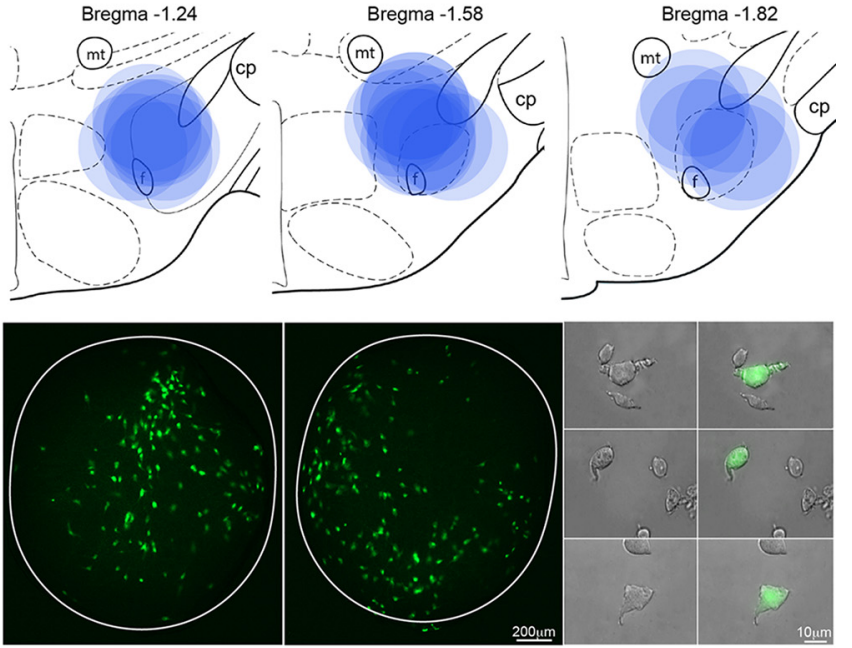

E
D

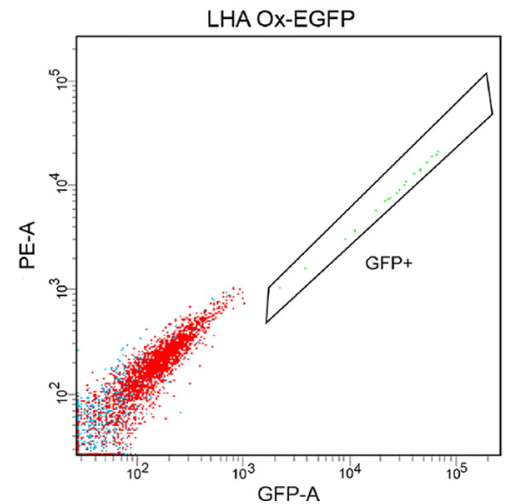

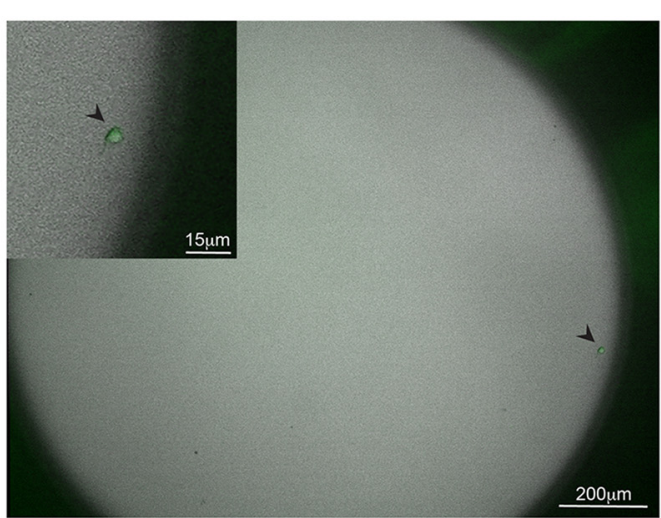

Figure 2. Microdissection of the LHA and isolation of single Ox-EGFP and Pmch-Cre;EYFP neurons. A, Schematic representation of microdissection and cell isolation procedure. $\boldsymbol{B}$, Schematic of the location of tissue punches from Ox-EGFP microdissections mapped onto serial mouse brain atlas images of the hypothalamus (top), representative bilateral tissue punches and isolated EGFP + and EGFP- neurons (bottom). C, Schematic of tissue punches from Pmch-Cre;EYFP microdissections (top), representative tissue punches and isolated EYFP+ and EYFP- neurons (bottom). $\boldsymbol{D}$, Representative FACS sort of Ox-EGFP neurons showing fluorescence gates for PE-A versus GFP-A showing GFP gate. $\boldsymbol{E}$, Brightfield and fluorescent micrograph of a representative single Ox-EGFP neuron isolated via FACS in a single well of a Terasaki plate. Higher magnification image of the same Ox-EGFP neuron in the upper left corner inset. 
Table 1. Panel of 48 genes used to probe the neurochemical profile of Hcrt/Ox and $\mathrm{MCH}$ neurons

\begin{tabular}{|c|c|c|c|}
\hline Gene name/common protein abbreviation & Gene symbol & Function & TaqMan primer sequence \\
\hline Glyceraldehyde-3-phosphate dehydrogenase (GAPDH) & Gapdh & Housekeeping & Mm03302249_g1 \\
\hline Hypoxanthine guanine phosphoribosyl transferase (HPRT) & Hprt & Housekeeping & Mm03024075_m1 \\
\hline Neuronal nuclei (NeuN) & Rbfox3 & Neuronal marker & Mm01248781_m1 \\
\hline Microtubule associated protein 2 (MAP2) & Map2 & Neuronal marker & Mm00485231_m1 \\
\hline Tubulin beta 3 (TuJ1) & Tubb3 & Neuronal marker & Mm00727586_s1 \\
\hline Glial fibrillary acidic protein (GFAP) & Gfap & Glial marker & Mm01253033_m1 \\
\hline S100 calcium binding protein B $(\mathrm{S} 100 \beta)$ & S100b & Glial marker & Mm00485897_m1 \\
\hline Hypocretin/orexin (Hcrt/Ox) & Hcrt & Neuropeptide & Mm01964030_s1 \\
\hline Pro-melanin-concentrating hormone (MCH) & Pmch & Neuropeptide & Mm01242886_g1 \\
\hline Prodynorphin (DYN) & Pdyn & Neuropeptide & Mm00457573_m1 \\
\hline Galanin (GAL) & Gal & Neuropeptide & Mm00439056_m1 \\
\hline Neurotensin (NTS) & Nts & Neuropeptide & Mm00481140_m1 \\
\hline Nucleobindin 2 (Nesfatin-1 or NUCB2) & Nucb2 & Neuropeptide & Mm01137144_m1 \\
\hline Cocaine and amphetamine regulatory transcript (CART) & Cartpt & Neuropeptide & Mm04210469_m1 \\
\hline Thyrotropin-releasing hormone (TRH) & Trh & Neuropeptide & Mm01182425_g1 \\
\hline Prepronociceptin/orphanin FQ (N/OFQ) & Pnoc & Neuropeptide & Mm01314909_m1 \\
\hline Corticotropin-releasing hormone (CRF) & $\mathrm{Crh}$ & Neuropeptide & Mm01293920_s1 \\
\hline Proenkephalin (PENK) & Penk & Neuropeptide & Mm01212875_m1 \\
\hline Substance $\mathrm{P}$ (SubP) & Tac1 & Neuropeptide & Mm01166996_m1 \\
\hline Tachykinin2 (TAC2) & Tac2 & Neuropeptide & Mm01160362_m1 \\
\hline Somatostatin (SST) & Sst & Neuropeptide & Mm00436671_m1 \\
\hline Glutamate decarboxylase 2 (GAD65) & Gad2 & GABA synthesis & Mm00484623_m1 \\
\hline Glutamate decarboxylase 1 (GAD67) & Gad1 & GABA synthesis & Mm04207432_g1 \\
\hline Vesicular GABA transporter (VGAT) & Slc32a1 & GABA release & Mm00494138_m1 \\
\hline Vesicular glutamate transporter 1 (VGLUT1) & Slc17a7 & Glutamate release & Mm00436577_m1 \\
\hline Vesicular glutamate transporter 2 (VGLUT2) & Slc17a6 & Glutamate release & Mm00499876_m1 \\
\hline Vesicular glutamate transporter 3 (VGLUT3) & Slc17a8 & Glutamate release & Mm00805413_m1 \\
\hline Vesicle Monoamine Transporter 1 (VMAT1) & Slc18a1 & Monoamine release & Mm00461868_m1 \\
\hline Vesicle Monoamine Transporter 2 (VMAT2) & Slc18a2 & Monoamine release & Mm00553058_m1 \\
\hline Glutaminase (GLS) & Gls & Glutamate synthesis & Mm01257297_m1 \\
\hline Choline acetyltransferase (ChAT) & Chat & Acetylcholine synthesis & Mm01221880_m1 \\
\hline Tyrosine hydroxylase $(\mathrm{TH})$ & $T h$ & Catecholamine synthesis & Mm00447557_m1 \\
\hline Histidine decarboxylase (HDC) & Hdc & Histamine synthesis & Mm00456104_m1 \\
\hline Tryptophan hydroxylase 1 (TPH1) & Tph1 & Serotonin synthesis & Mm01202614_m1 \\
\hline Tryptophan hydroxylase 2 (TPH2) & Tph2 & Serotonin synthesis & Mm00557715_m1 \\
\hline Adenosine deaminase (ADA) & Ada & Adenosine metabolism & Mm00545720_m1 \\
\hline Parvalbumin (PV) & Pvalb & Calcium-binding protein & Mm00443100_m1 \\
\hline Calretinin (CR) & Calb2 & Calcium-binding protein & Mm00801461_m1 \\
\hline Calbindin (CALB) & Calb1 & Calcium-binding protein & Mm00486647_m1 \\
\hline NK2 homeobox 1 (NKX2.1) & $N k \times 2-1$ & Transcription factor & Mm00447558_m1 \\
\hline LIM homeobox 9 (LHX9) & Lhx9 & Transcription factor & Mm00495308_m1 \\
\hline Neuronal pentraxin 2 (NPTX2) & Nptx2 & Synaptic function & Mm00479438_m1 \\
\hline Insulin-like growth factor binding protein 3 (IGFBP3) & $\operatorname{lgfbp3}$ & Growth factor binding & Mm01187817_m1 \\
\hline CUGBP, Elav-like family member 6 (CELF6) & Celf6 & RNA binding & Mm01176134_m1 \\
\hline Neuronatin (NNAT) & Nnat & Ion channel function & Mm00731416_s1 \\
\hline Leptin receptor (LEPR) & Lepr & Receptor & Mm00440181_m1 \\
\hline Ghrelin receptor (GHSR) & Ghsr & Receptor & Mm00616415_m1 \\
\hline Melanocortin 4 receptor (MC4-R) & $M c 4 r$ & Receptor & Mm00457483_s1 \\
\hline
\end{tabular}

Ox-EGFP neurons that went on to further qPCR analysis using the full 48-gene panel.

\section{Single-cell qPCR for transcripts of 48 key genes in $\mathrm{Hcrt} / \mathrm{Ox}$ and $\mathrm{MCH}$ neurons}

Following single-cell qPCR, with an output of inverted Ct values plotted on a $\log _{2}$-based scale, we first asked what proportion of neurons sorted from Ox-EGFP mice expressed Hcrt, and what proportion of Pmch-Cre;EYFP neurons expressed Pmch. We found that virtually every labeled and sorted Ox-EGFP neuron (98.6\%; 69/70) that passed our Gapdh prescreen, robustly expressed Hcrt (the $1 \mathrm{Hcrt}$ - cell was removed from the dataset), and every labeled and sorted Pmch-Cre;EYFP neuron (100\%; 89/89) expressed Pmch, although we observed variability in Pmch expression levels. Nevertheless, these data indicate that our dissociation and FACS-sorting procedure, using Ox-EGFP and Pmch-Cre;EYFP transgenic lines, is capable of isolating cells that appear to faithfully and selectively express transcripts for their defining neuropeptides.

We then asked whether the gene expression profiles of $\mathrm{Hcrt} / \mathrm{Ox}$ and $\mathrm{MCH}$ neurons are distinct or overlapping based on our 48-gene panel. To do this, we performed unsupervised hierarchical clustering using Ward's method with complete linkage (Fig. $3 A$ ). We found that Hcrt/Ox 


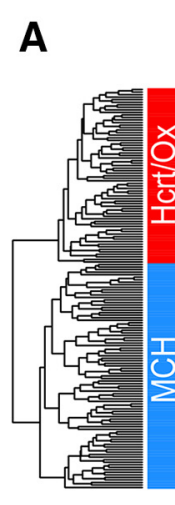

$\log _{2}$ Expression $0 \quad 5 \quad 10 \quad 1525$

B
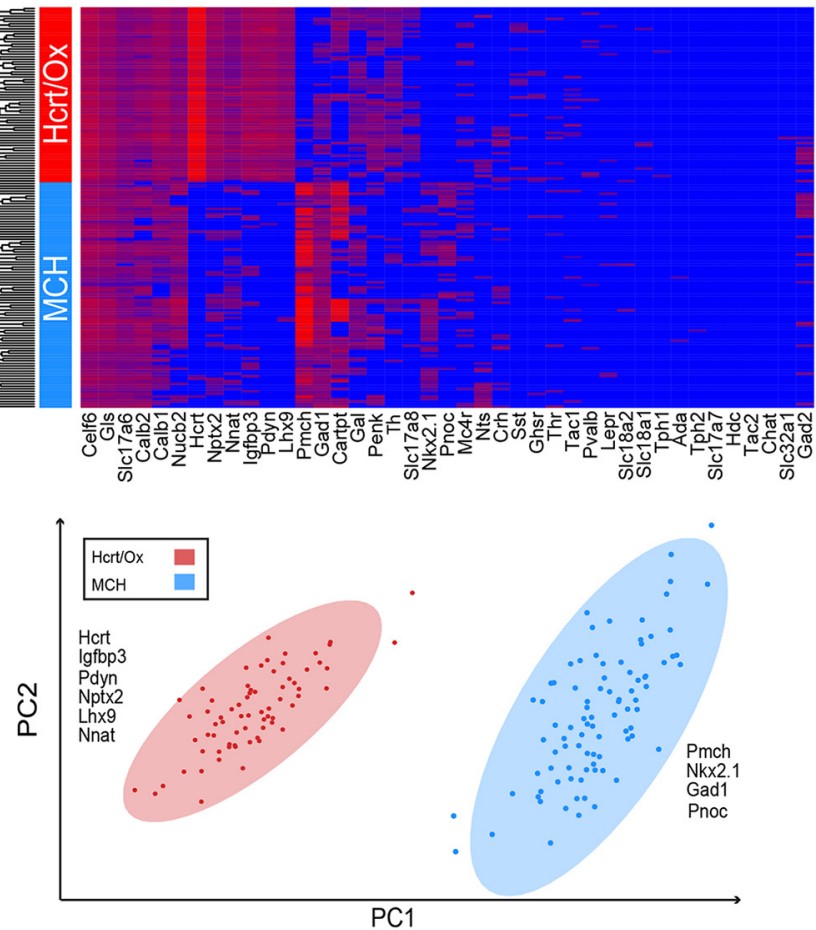

C

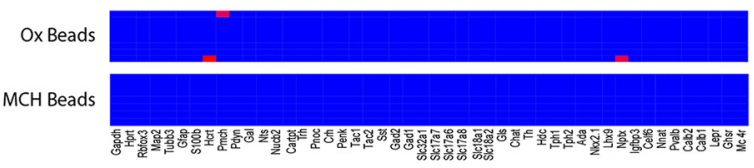

D

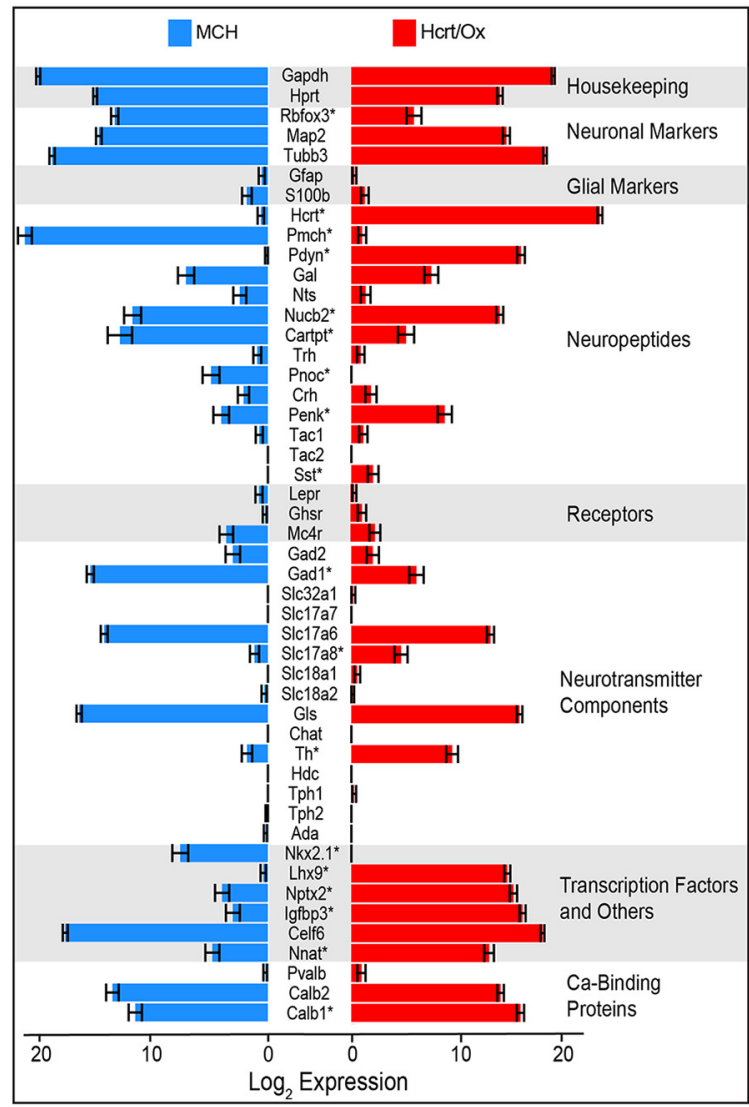

Figure 3. Single-cell qPCR of 48 genes in Hcrt/Ox and $\mathrm{MCH}$ neurons. A, Unsupervised hierarchical clustering heatmap of $89 \mathrm{MCH}$ and $69 \mathrm{Hcrt} / \mathrm{Ox}$ single cells measured for the expression of 41 genes by qPCR. Genes not represented in this heatmap are housekeeping genes, neuronal and glial markers (Gapdh, Hprt, Rbfox3, Map2, Tubb3, Gfap, and S100b). Heatmap colors depict expression levels on a $\log _{2}$ scale from low (blue) to high (red). $\boldsymbol{B}$, Principal component analysis (PCA) using the same cells and genes as in $\boldsymbol{A}$. Ellipses denote 95\% coverage for the populations indicated. Gene names represent transcripts enriched in each population based on the top loading scores from the first principal component. $\boldsymbol{C}$, Manually ordered heatmap showing 48 gene qPCR of APC bead negative controls from Hcrt/Ox and $\mathrm{MCH}$ cell preparations. $\boldsymbol{D}$, Bar chart of averaged $\log _{2}$ expression values for 48 genes in $\mathrm{Hcrt} / \mathrm{Ox}$ and $\mathrm{MCH}$ cells organized by molecular function. Error bars represent standard error of the mean (s.e.m.) for each sample/gene. Asterisks $(*)$ denote statistically significant proportional difference using Fisher's exact test, adjusted $p<0.05$ (from Table 2) and the Benjamini-Hochberg procedure to control false discovery rate (FDR) at $5 \%$. In all panels, red denotes Hcrt/Ox neurons and blue denotes $\mathrm{MCH}$ neurons.

and $\mathrm{MCH}$ neurons separated into entirely distinct clusters corresponding to labeled cells isolated from Ox-EGFP and Pmch-Cre;EYFP mice as shown in the combined heatmap of gene expression in the two populations (Fig. $3 A$ ). Genes not represented in this heatmap are housekeeping genes, neuronal and glial markers (Table 1) as well as other genes that are virtually undetectable in both cell populations (Chat, Hdc, S/c17a7 and Tac2). Genes in this analysis fall into three distinct categories: uniformly expressed in most if not all single cells (e.g., Celf6, Gls, Calb1, Calb2, etc.), low/undetectable expression (e.g., Tph1, Tph2, Ada, etc.) or differentially expressed between the two populations (e.g., Hcrt, Pmch, Lhx9, Nkx2.1, etc.). Subsequent sections will focus specifically on these differentially expressed genes and their contribution to $\mathrm{Hcrt} / \mathrm{Ox}$ and $\mathrm{MCH}$ neurochemical identity.
To formally determine which genes differentiate the $\mathrm{Hcrt} / \mathrm{Ox}$ and $\mathrm{MCH}$ neuronal populations based on our 48-gene panel, we performed principal component analysis (PCA) and examined the loadings of genes on the PC axes. In our PCA of the single-cell qPCR data, Hcrt/Ox and $\mathrm{MCH}$ neurons separate clearly along the first principal component (PC1) into distinct clusters on the basis of several key markers (Fig. 3B). The variance captured in PC1 accounts for $26 \%$ of the total variance in the dataset. This is in contrast to PC2, which largely captures the within-group variation in $\mathrm{Hcrt} / \mathrm{Ox}$ and $\mathrm{MCH}$ cells, which only captures $8.5 \%$ of the total variance. Ellipses represent $95 \%$ coverage for each population. Not surprisingly, Pmch and Hcrt are the most discriminatory markers that differentiate each cluster from one another and show mutually exclusive expression patterns, further confirming 
that these two populations are nonoverlapping. Hcrt/Ox neurons are further distinguished by the expression of key discriminatory genes (Igfbp3, Pdyn, Nptx2, Lhx9, and Nnat), confirming previous molecular and anatomic characterizations of Hcrt/Ox neurons (Reti et al., 2002; Crocker et al., 2005; Honda et al., 2009; Shimogori et al., 2010; Dalal et al., 2013; Liu et al., 2015; Sokolowski et al., 2015). However, many of these same markers were also expressed in $\mathrm{MCH}$ neurons to varying extents. In particular, we found that Celf6, a gene that encodes an RNA-binding protein implicated in autism-related behavior (Dougherty et al., 2013) and found to be widely expressed in neuromodulatory cell types throughout the mouse brain (Maloney et al., 2016), is expressed in all $\mathrm{Hcrt} / \mathrm{Ox}$ and $\mathrm{MCH}$ neurons. In our PCA analysis, we found that $\mathrm{MCH}$ neurons are defined by the expression of other discriminatory genes (Nkx2.1, Gad1, and Pnoc). The highly specific expression of $N k \times 2.1$ in $\mathrm{MCH}$ neurons is consistent with previous molecular and anatomic work (Croizier et al., 2011). We note that using PCA analysis, we found that neither Hcrt/Ox nor $\mathrm{MCH}$ populations form clear subclusters attributable to the expression of specific discriminatory genes, implying a lack of discrete subpopulations, at least based on our limited 48-gene panel.

We next addressed two potential confounds in the interpretation of our data. One is whether we have sufficient statistical power to quantitatively evaluate differential gene expression between $\mathrm{Hcrt} / \mathrm{Ox}$ and $\mathrm{MCH}$ neurons. Another is whether there are systematic batch effects within each population. To address the first point, we performed power analysis via simulation (see Materials and Methods) to determine if the numbers of neurons we collected for each population are adequate to achieve sufficient statistical power. We found that with the sample sizes of each population (69 and 89) used in this study, Fisher's exact test (Agresti, 1992) has adequate power $(>90 \%)$ to detect differential gene expression between the two types of neurons for even moderate effect sizes.

To address the issue of batch effects, we used two complementary approaches. First, we used multiple hypothesis testing to examine whether there is a systematic difference between the two batches within each condition. Specifically, for each population, and for each of the 48 genes, we used Fisher's exact test (Agresti, 1992) to assess whether the probability of gene expression is the same in the two batches. The Benjamini-Hochberg procedure (Benjamini and Hochberg, 1995) was used to control the FDR at $5 \%$. For Hcrt/Ox neurons, only one gene (Rbfox3) shows significant difference among the two batches when the FDR is controlled at $5 \%$. For $\mathrm{MCH}$ neurons, three genes (Gal, Trh, and Nnat) show significant difference among the two batches when the FDR is controlled at $5 \%$. Therefore, we found minimal systematic difference between two batches of data for each population. We also performed PCA analysis of batch-effects within each population and found that cells from different collections share nearly identical gene expression patterns and these differences do not contribute to the differences between the Hcrt/Ox and $\mathrm{MCH}$ neuron populations.
Finally, another potential confound in our single-cell analysis is the possibility that the droplet of media that accompanies FACS-sorted single cells is a source of contaminating, ambient mRNA from ruptured cells in the cell suspension. To address this possibility, we added fluorescent APC beads to the single-cell suspensions from each population and sorted single beads using parameters described above. Single sorted beads, eight from each condition, were subjected to qPCR alongside our cell samples. Beads sorted from Pmch-Cre;EYFP preparations yielded undetectable levels of any of the 48 genes in our panel. Among beads sorted from Ox-EGFP preparations, a single bead contained detectable levels of Hcrt and Nptx2 while another bead contained detectable levels of Pmch. These data demonstrate that media contamination is unlikely to contribute to the patterns of gene expression we observed in our single-cell qPCR analysis.

\section{Differential gene expression between Hcrt/Ox and $\mathrm{MCH}$ neurons}

Having demonstrated that $\mathrm{Hcrt} / \mathrm{Ox}$ and $\mathrm{MCH}$ neurons are transcriptionally distinct on the basis of our 48-gene panel, we averaged the single-cell expression values from each population to more clearly describe differential gene expression (Fig. 3D). Aside from housekeeping genes (Gapdh and Hprt), Hcrt/Ox and MCH neurons show robust expression of neuronal markers (Tubb3, NeuN, and Map2) and minimal expression of glial markers (Gfap and S100b), further demonstrating that our capture of single, labeled neurons was largely free of glial contamination. Other broad categories of genes (neuropeptides, receptors, neurotransmitter components etc.) exhibited striking patterns of both common and differential gene expression. To complement average expression level, we quantified proportional difference in gene expression using Fisher's exact test (Agresti, 1992) to examine whether the probability of gene expression is different among the two populations, while the Benjamini-Hochberg procedure (Benjamini and Hochberg, 1995) was used to control the FDR at $5 \%$. Table 2 shows all 48 genes in descending order of proportional difference, with significance level indicated as adjusted $p$ value. Differential gene expression will be addressed in more detail in the subsequent discussion of the coexpression of neuropeptides (Figs. 5, 6) and fast neurotransmitter components (Figs. 7, 8). Taken together, our single-cell qPCR analysis thus indicates that our procedure for isolating single, intact, FACSsorted Hcrt/Ox and $\mathrm{MCH}$ neurons from two transgenicallylabeled mouse lines is selective and robust, with minimal contamination by glial cells and ambient transcripts in the media.

\section{Comparison of single-cell qPCR analysis of Hcrt/Ox neurons with bulk TRAP/microarray data}

As further validation of the pattern of gene expression that we observed in our single-cell qPCR analysis of Hcrt/Ox neurons, we compared our dataset with a previously described bulk transcriptomic analysis of Hcrt/Ox neurons (Dalal et al., 2013). In this work, Dalal and coauthors generated a novel transgenic mouse line (Hcrt: 
Table 2. Proportional difference in expression of all 48 genes in Hcrt/Ox and MCH neurons

\begin{tabular}{|c|c|c|c|c|}
\hline Gene symbol & $\begin{array}{l}\text { Proportion in } \\
\mathrm{MCH} \text { neurons }\end{array}$ & $\begin{array}{l}\text { Proportion in } \\
\text { Hcrt/Ox neurons }\end{array}$ & $\begin{array}{l}\text { Absolute proportional } \\
\text { difference (\%) }\end{array}$ & $\begin{array}{l}\text { Adjusted } \\
p \text { value }\end{array}$ \\
\hline Pdyn & $1 / 89$ & $69 / 69$ & 99.0 & $5.12 \mathrm{E}-43 *$ \\
\hline Lhx9 & $3 / 89$ & $69 / 69$ & 97.0 & $2.18 \mathrm{E}-40 *$ \\
\hline Hcrt & $5 / 89$ & $69 / 69$ & 94.0 & 3.93E-38* \\
\hline Pmch & $89 / 89$ & $6 / 69$ & 91.0 & 1.59E-36* \\
\hline lgfbp3 & $20 / 89$ & $69 / 69$ & 78.0 & $6.90 \mathrm{E}-26 *$ \\
\hline$T h$ & $14 / 89$ & $60 / 69$ & 71.0 & $1.84 \mathrm{E}-19 *$ \\
\hline Nptx2 & $29 / 89$ & $69 / 69$ & 67.0 & $7.82 \mathrm{E}-21 *$ \\
\hline Nkx2.1 & $54 / 89$ & $0 / 69$ & 61.0 & $9.11 \mathrm{E}-18 *$ \\
\hline Nnat & $39 / 89$ & $68 / 69$ & 55.0 & $1.78 \mathrm{E}-14 *$ \\
\hline Penk & $26 / 89$ & $53 / 69$ & 48.0 & 1.43E-08* \\
\hline$R b f o x 3$ & $86 / 89$ & $37 / 69$ & 43.0 & $1.81 \mathrm{E}-10 *$ \\
\hline Gad1 & $87 / 89$ & $39 / 69$ & 41.0 & $1.87 \mathrm{E}-10 *$ \\
\hline Slc17a8 & $8 / 89$ & $33 / 69$ & 39.0 & 1.30E-07* \\
\hline Pnoc & $31 / 89$ & $0 / 69$ & 35.0 & $5.08 \mathrm{E}-09 *$ \\
\hline Nucb2 & $68 / 89$ & $69 / 69$ & 24.0 & $6.23 \mathrm{E}-06 *$ \\
\hline Cartpt & $59 / 89$ & $29 / 69$ & 24.0 & 9.39E-03* \\
\hline Sst & $0 / 89$ & $14 / 69$ & 20.0 & 1.21E-05* \\
\hline $\mathrm{Gal}$ & $49 / 89$ & $49 / 69$ & 16.0 & $>0.05$ \\
\hline Calb1 & $76 / 89$ & $69 / 69$ & 15.0 & 1.70E-03* \\
\hline Calb2 & $80 / 89$ & $68 / 69$ & 9.0 & $>0.05$ \\
\hline Ghsr & $2 / 89$ & $7 / 69$ & 8.0 & $>0.05$ \\
\hline$M c 4 r$ & 27/89 & $16 / 69$ & 7.0 & $>0.05$ \\
\hline Slc18a1 & $0 / 89$ & $4 / 69$ & 6.0 & $>0.05$ \\
\hline Pvalb & $2 / 89$ & $6 / 69$ & 6.0 & $>0.05$ \\
\hline Nts & $16 / 89$ & $8 / 69$ & 6.0 & $>0.05$ \\
\hline Tac1 & $6 / 89$ & $8 / 69$ & 5.0 & $>0.05$ \\
\hline Gad2 & $19 / 89$ & $11 / 69$ & 5.0 & $>0.05$ \\
\hline Tph1 & $0 / 89$ & $2 / 69$ & 3.0 & $>0.05$ \\
\hline Slc17a6 & $87 / 89$ & $69 / 69$ & 2.0 & $>0.05$ \\
\hline Ada & $2 / 89$ & $0 / 69$ & 2.0 & $>0.05$ \\
\hline Lepr & $6 / 89$ & $3 / 69$ & 2.0 & $>0.05$ \\
\hline Crh & $16 / 89$ & $11 / 69$ & 2.0 & $>0.05$ \\
\hline s100b & $16 / 89$ & $11 / 69$ & 2.0 & $>0.05$ \\
\hline Gfap & $4 / 89$ & $2 / 69$ & 2.0 & $>0.05$ \\
\hline Slc32a1 & $0 / 89$ & $1 / 69$ & 1.0 & $>0.05$ \\
\hline Map2 & $88 / 89$ & $69 / 69$ & 1.0 & $>0.05$ \\
\hline Tph2 & $1 / 89$ & $0 / 69$ & 1.0 & $>0.05$ \\
\hline Trh & $7 / 89$ & $6 / 69$ & 1.0 & $>0.05$ \\
\hline Slc18a2 & $2 / 89$ & $1 / 69$ & 1.0 & $>0.05$ \\
\hline Hprt & $89 / 89$ & $69 / 69$ & 0.0 & $>0.05$ \\
\hline Gapdh & $89 / 89$ & $69 / 69$ & 0.0 & $>0.05$ \\
\hline Slc17a7 & $0 / 89$ & $0 / 69$ & 0.0 & $>0.05$ \\
\hline $\mathrm{Hdc}$ & 0/89 & $0 / 69$ & 0.0 & $>0.05$ \\
\hline Tac2 & $0 / 89$ & $0 / 69$ & 0.0 & $>0.05$ \\
\hline Tubb3 & $89 / 89$ & $69 / 69$ & 0.0 & $>0.05$ \\
\hline Gls & $89 / 89$ & $69 / 69$ & 0.0 & $>0.05$ \\
\hline Chat & $0 / 89$ & $0 / 69$ & 0.0 & $>0.05$ \\
\hline Celf6 & $89 / 89$ & $69 / 69$ & 0.0 & $>0.05$ \\
\hline
\end{tabular}

Asterisks (*) denote significant difference (Fisher's exact text and Benjamini-Hochberg procedure to control FDR at 5\%).

eGFP-RpL10a), isolated ribosome-bound transcripts from homogenized diencephalon through translating ribosome affinity purification (TRAP) methodology, followed by systematic translational profiling through microarrays. Using this published data, we identified 41 genes that were common to both their dataset and our gene panel and directly compared their gene expression values with our averaged single-cell qPCR data (Fig. 4). We found a strong positive linear correlation between these two datasets, with a Spearman's correlation coefficient $\rho=0.71$ $\left(p=1.2 \times 10^{-8}\right)$. Among the most strongly correlated genes were Hcrt, Pdyn, Nptx2, Igfbp3, Lhx9, and Nnat, all known to be enriched in Hcrt/Ox neurons from Dalal et al. (2013) and from previous work (Reti et al., 2002; Crocker et al., 2005; Honda et al., 2009; Shimogori et al., 2010; Liu et al., 2015; Sokolowski et al., 2015). This robust correlation of known discriminatory markers, observed using two independent methodologies and transgenic reagents, is additional supportive evidence that our single-cell qPCR approach is capable of capturing pure populations of rare and intermingled neuropeptidergic neurons within the LHA. 


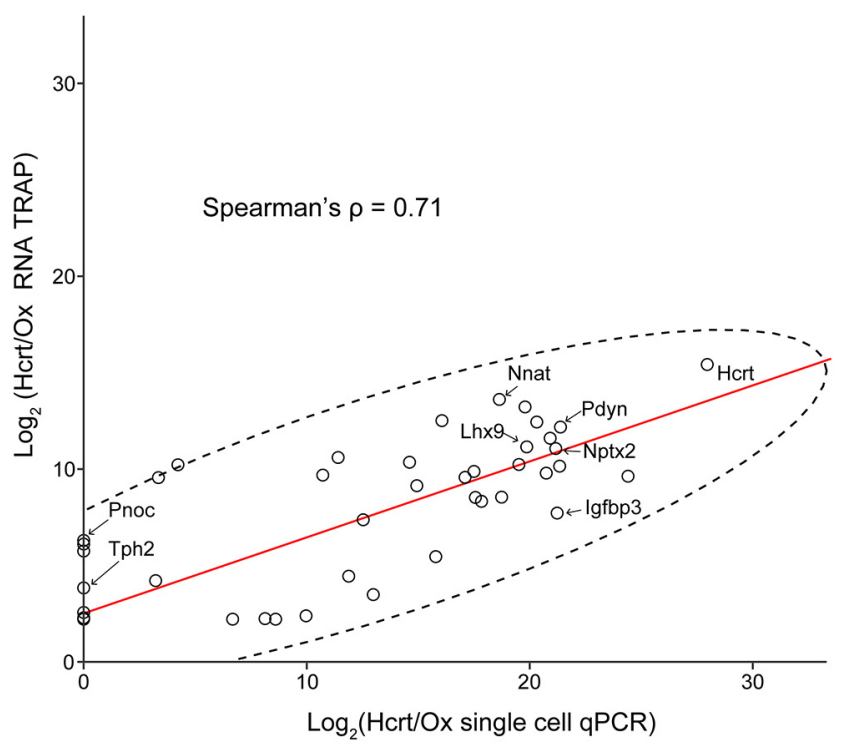

Figure 4. Comparison of single-cell qPCR data to previously published RNA-TRAP dataset. Scatterplot showing expression of all 41 genes measured in both our single-cell qPCR dataset ( $x$-axis) and in a previously published bulk RNA TRAP experiment ( $y$-axis; Dalal et al., 2013). The two datasets show strong correlation (Spearman's $\rho=0.71 ; p=1.2 \times 10^{-8}$ ), the red line depicts the Spearman's correlation, dotted ellipse denotes $95 \%$ coverage of the data points.

\section{Neuropeptide and receptor expression varies widely in specificity and abundance among Hcrt/Ox and $\mathrm{MCH}$ neuron populations}

We next sought to determine how the expression of 14 neuropeptides (Hcrt, Pmch, Cartpt, Nucb2, Gal, Pnoc, Penk, Nts, Crh, Tac1, Tac2, Sst, Trh, and Pdyn) and three key peptide receptors (Lepr, Ghsr, and Mc4r) was distributed between $\mathrm{MCH}$ and Hcrt/Ox neuron populations (Fig. 5; Table 2). We asked whether these 17 neuropeptide/receptor markers exhibited mutually exclusive expression patterns or were common to both populations. For both $\mathrm{MCH}$ and Hcrt/Ox neurons, we visualized patterns of coexpression among the individual neuropeptide/receptor markers in hierarchically-clustered heatmaps (Fig. $5 A, B$ ), correlation matrices (Fig. 5C,D), and bubble plots (Fig. 5E).

As described above, we found that every labeled and sorted Ox-EGFP neuron expressed Hcrt and every labeled and every sorted Pmch-Cre;EYFP neuron expressed Pmch to varying degrees (Fig. 5; Table 2). However, we also found that a small number of Hcrt/Ox neurons also expressed Pmch (8.7\%), and an even smaller number of $\mathrm{MCH}$ neurons also expressed Hcrt (5.6\%; Fig. 5; Table 2). This potential crosstalk is mitigated by our observation of highly selective expression of two key discriminatory transcription factors, Lhx9 in Hcrt/Ox neurons $(100 \%$ in $\mathrm{Hcrt} / \mathrm{Ox}$ neurons; $3.4 \%$ in $\mathrm{MCH}$ neurons) and $N k \times 2.1$ in $\mathrm{MCH}$ neurons $(60.1 \%$ in $\mathrm{MCH}$ neurons; $0 \%$ in Hcrt/Ox neurons; Fig. 3D; Table 2).

Among $\mathrm{MCH}$ neurons, the most extensively coexpressed neuropeptide transcripts, in descending order, were Nucb2 (76.4\%), Cartpt (66.3\%), Gal (55.0\%), Pnoc (34.8\%), and Penk (29.2\%; Fig. 5; Table 2) reflected in the clustering observed in the correlation matrix (Fig. 5C). Neuropeptide transcripts that exhibited particularly low expression levels in $\mathrm{MCH}$ neurons include Sst $(0 \%)$, Tac2 (0\%), Pdyn (1.1\%), and Trh (7.9\%). Among Hcrt/Ox neurons, the most extensively coexpressed neuropeptide transcripts in our panel were Pdyn (100\%), Nucb2 (100\%), Penk (76.8\%), and Cartpt (42.0\%; Fig. 5; Table 2). Neuropeptide transcripts that exhibited notably low expression levels in Hcrt/Ox neurons include Tac2 (0\%), Pnoc (0\%), and $\operatorname{Trh}(8.7 \%)$.

Neuropeptides/receptors exhibit varying degrees of specificity and abundance within the $\mathrm{MCH}$ and Hcrt/ Ox populations, summarized in a bubble plot (Fig. $5 E$; Table 2). For example, Pdyn is unsurprisingly both highly abundant and highly specific to Hcrt/Ox neurons, consistent with previous work (Chou et al., 2001; Muschamp et al., 2014) and the only neuropeptide transcript to exhibit this profile. Other neuropeptides (Sst and Pnoc), although much less abundant, also exhibit highly specific differential expression (Sst in a small subpopulation of $\mathrm{Hcrt} / \mathrm{Ox}$ neurons and Pnoc in a subpopulation of $\mathrm{MCH}$ neurons). Our observation that Pnoc, encoding nociceptin/orphanin FQ (N/OFQ), exhibits moderate to low expression in $\mathrm{MCH}$ but is undetectable in Hcrt/Ox neurons, contrasts with a previous report showing that N/OFQ-IR is found in most Hcrt/Ox but not $\mathrm{MCH}$ neurons in the rat (Maolood and Meister, 2010), but is consistent with a study showing that N/OFQ-IR and Hcrt/Ox-IR neurons are intermingled but separate (Gerashchenko et al., 2011). Other neuropeptides (Cartpt and Penk) are abundant and show only moderate specificity, with Cartpt being moderately specific to $\mathrm{MCH}$ neurons, with clear Cartpt+ and Cartpt- subpopulations (especially prominent in Fig. $5 A$ ), while Penk is moderately specific to Hcrt/Ox neurons. Detailed analyses in rodents demonstrated extensive and selective expression of Cartpt in a subpopulation of $\mathrm{MCH}$ neurons, with little to no expression in Hcrt/Ox neurons (Broberger, 1999; Vrang et al., 1999; Brischoux et al., 2001; Elias et al., 2001; Cvetkovic et al., 2004). Penk expression has been reported in the rat LHA (Abrahamson and Moore, 2001; Horjales-Araujo et al., 2014), although colocalization with Hcrt/Ox and $\mathrm{MCH}$ neurons has not been previously shown.

In contrast, other neuropeptide transcripts were either abundant or absent from both populations. Nucb2 shows significantly higher expression in Hcrt/Ox neurons (Table 2) but is highly abundant in both populations, in contrast to previous work showing strong specificity for $\mathrm{MCH}$ neurons (Foo et al., 2008; Fort et al., 2008). Gal was also relatively abundant but seemingly nonspecific, contrasting with previous work (Laque et al., 2013). Similarly, other neuropeptide transcripts (Tac1, Crh, Nts, Trh) also show little specificity but are much less abundant, while Tac2 is undetectable in either population. Our failure to detect appreciable Nts transcript in Hcrt/Ox neurons contrasts with a previous report showing that a majority of $\mathrm{Hcrt} / \mathrm{Ox}$ neurons express Nts mRNA and NTS-IR (Furutani et al., 2013). Receptor expression in both populations is relatively low; Mc4r is expressed in small proportion of both populations with no specificity while both Ghsr and Lepr 

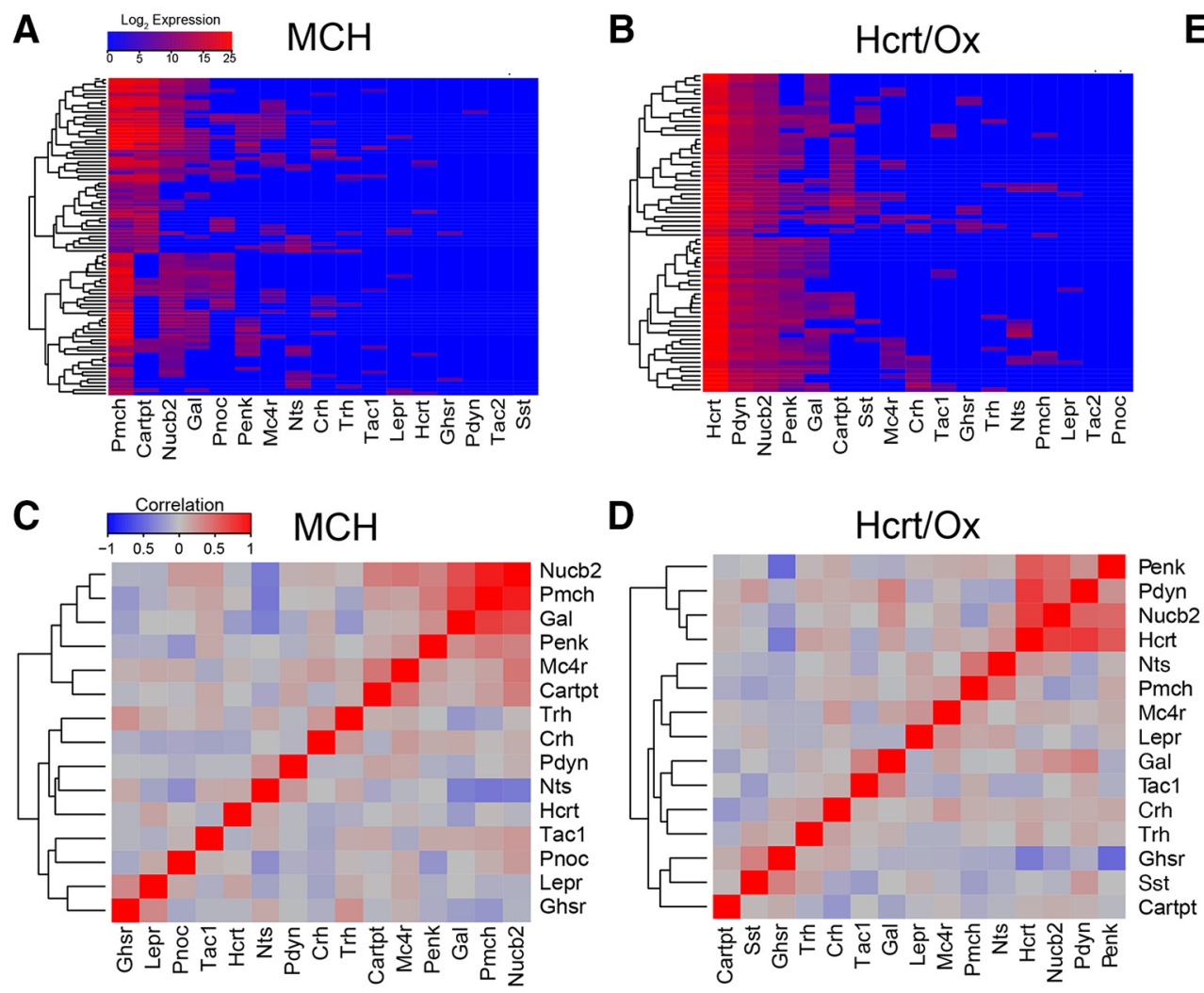

E

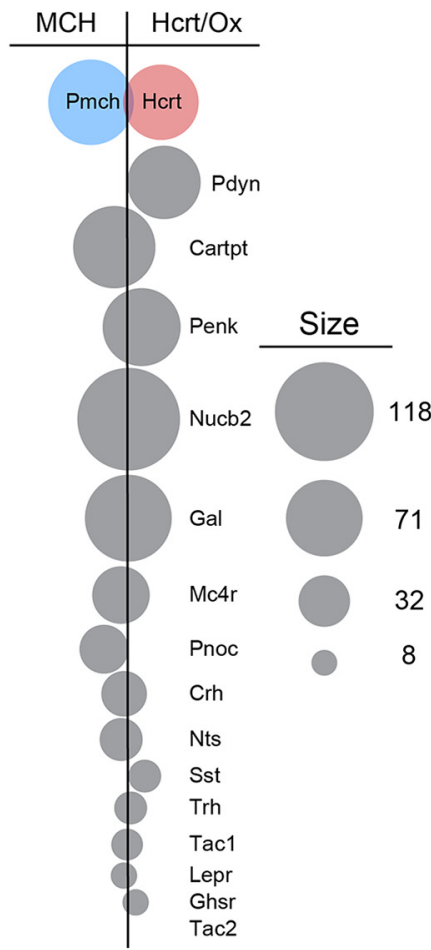

Figure 5. Analysis of neuropeptide and receptor coexpression patterns. $\boldsymbol{A}, \boldsymbol{B}$, Unsupervised hierarchical clustering heatmap of neuropeptide gene expression in $\mathrm{MCH}(\boldsymbol{A})$ and Hcrt/Ox $(\boldsymbol{B})$ neurons. $\boldsymbol{C}, \boldsymbol{D}$, Clustered heatmap of pairwise Pearson correlations between neuropeptides in $\mathrm{MCH}(\boldsymbol{C})$ and Hcrt/Ox $(\boldsymbol{D})$ neurons. $\boldsymbol{E}$, Bubble plot depicts the net difference in expression frequency for the neuropeptides indicated. Neuropeptides with a higher frequency of detection in $\mathrm{MCH}$ cells are shown to the left of the black line, higher frequency of detection in Hcrt/Ox cells to the right. Area of the circles represents the total number of cells from both populations expressing a given neuropeptide.

are neither abundant nor specific. The low expression of $M c 4 r$, Lepr, and Nts in either population is consistent with $\mathrm{MCH}$ and Hcrt/Ox neurons being entirely separate from overlapping populations of largely leptin-sensitive, neuropeptidergic LHA neurons (Leinninger et al., 2009, 2011; Cui et al., 2012; Laque et al., 2013). Taken together, these data suggest that both $\mathrm{Hcrt} / \mathrm{Ox}$ and $\mathrm{MCH}$ neurons exhibit a surprisingly high degree of coexpression with other neuropeptide transcripts, with only a few showing both high abundance and specificity for one population over another.

\section{In situ hybridization and immunohistochemical validation of neuropeptide coexpression in Hcrt/Ox and $\mathrm{MCH}$ neurons}

To validate the coexpression of neuropeptide mRNA in Hcrt- and Pmch-expressing neurons, we used dual FISH using the ACD RNAscope 2.5 Manual Assay for four key neuropeptides: Pdyn, Cartpt, Penk, and Nucb2, and measured percentage colocalization (Fig. $6 A-D, G-J$ ). Coronal LHA sections taken from juvenile wild type mice were counterstained with FISH probes and imaged using confocal microscopy. We confirmed a lack of colocalization of Pdyn mRNA with $\mathrm{MCH}$ neurons (0/47 cells; $0 \%)$ and extensive colocalization of Pdyn mRNA in Hcrt/Ox neurons (123/125 cells; 98.4\%; Fig. 6A,G). We found Cartpt
mRNA to colocalizes with $52.1 \%(99 / 190$ cells) of $\mathrm{MCH}$ neurons but only $8.4 \%$ (13/154 cells) of Hcrt/Ox neurons (Fig. 6B,H). Colocalization of Nucb2 mRNA was found in a majority of $\mathrm{MCH}(57 / 77$ cells; $74.0 \%)$ and Hcrt/Ox (76/90 cells; 84.4\%) neurons (Fig. 6C,I). We also observed limited overlap of Penk mRNA with both $\mathrm{MCH}$ (23/85 cells; $27.1 \%)$ and Hcrt/Ox (53/169 cells; 31.4\%) neurons (Fig. $6 D, J)$. We confirmed the presence of CART and nesfatin-1 (NUCB2) in $\mathrm{MCH}$ neurons using IHC, where Pmch-Cre; EYFP coronal brain slices were sectioned and stained for antibodies against either CART or NUCB2. We observed extensive colocalization of $\mathrm{MCH}$ neurons with CART-IR (60/126 cells, $47.6 \%)$ and complete colocalization of $\mathrm{MCH}$ neurons with NUCB2-IR (134/134 cells, 100.0\%; Fig $6 E, F)$. We similarly confirmed the presence of CART-IR and NUCB2-IR in Hcrt/Ox neurons using wild type coronal slices counterstained for an antibody against orexin $A$ and either CART or NUCB2. We confirmed robust colocalization of NUCB2-IR in Hcrt/Ox neurons (119/120 cells, 99.2\%), but did not observe robust CART-IR in Hcrt/Ox neurons $(1 / 115$ cells, $0.8 \%$; Fig. $6 K, L)$. This last observation contrasts with both our qPCR and FISH data and suggests that perhaps Hcrt/Ox neurons may contain Cartpt mRNA but little detectable protein. Nevertheless, both our FISH and IHC data are broadly consistent with 

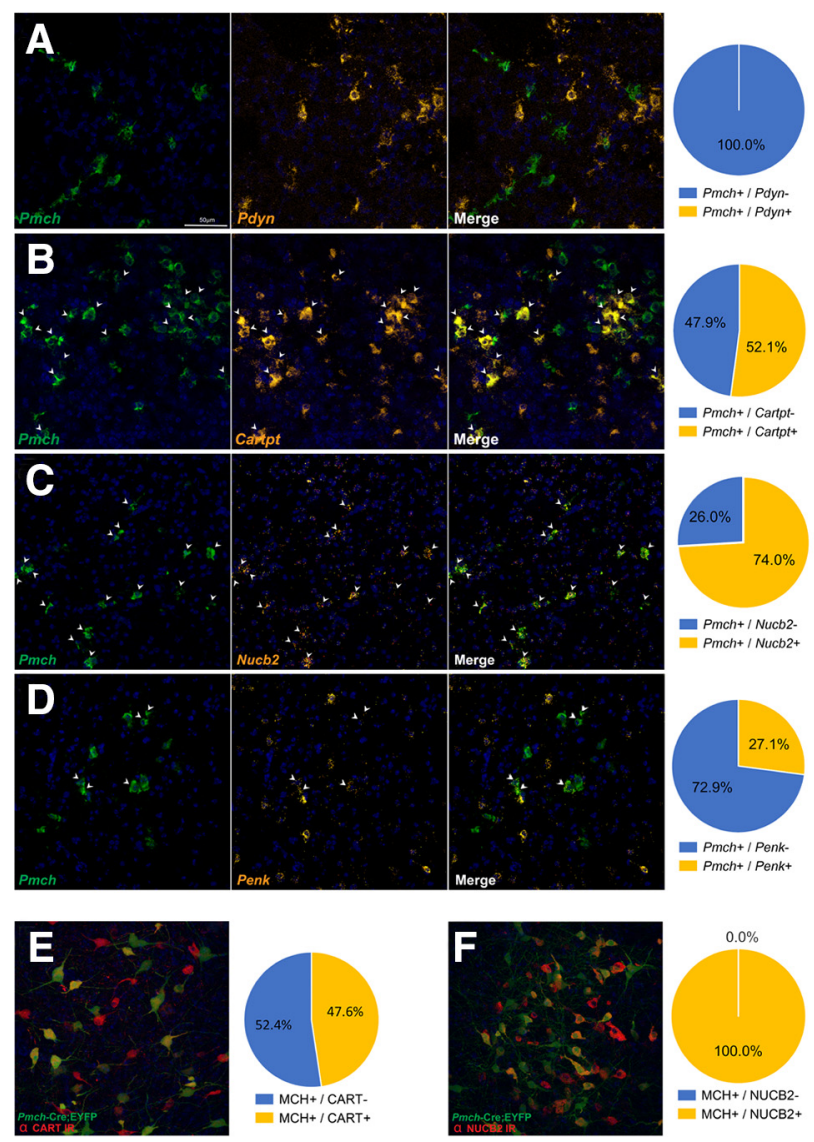
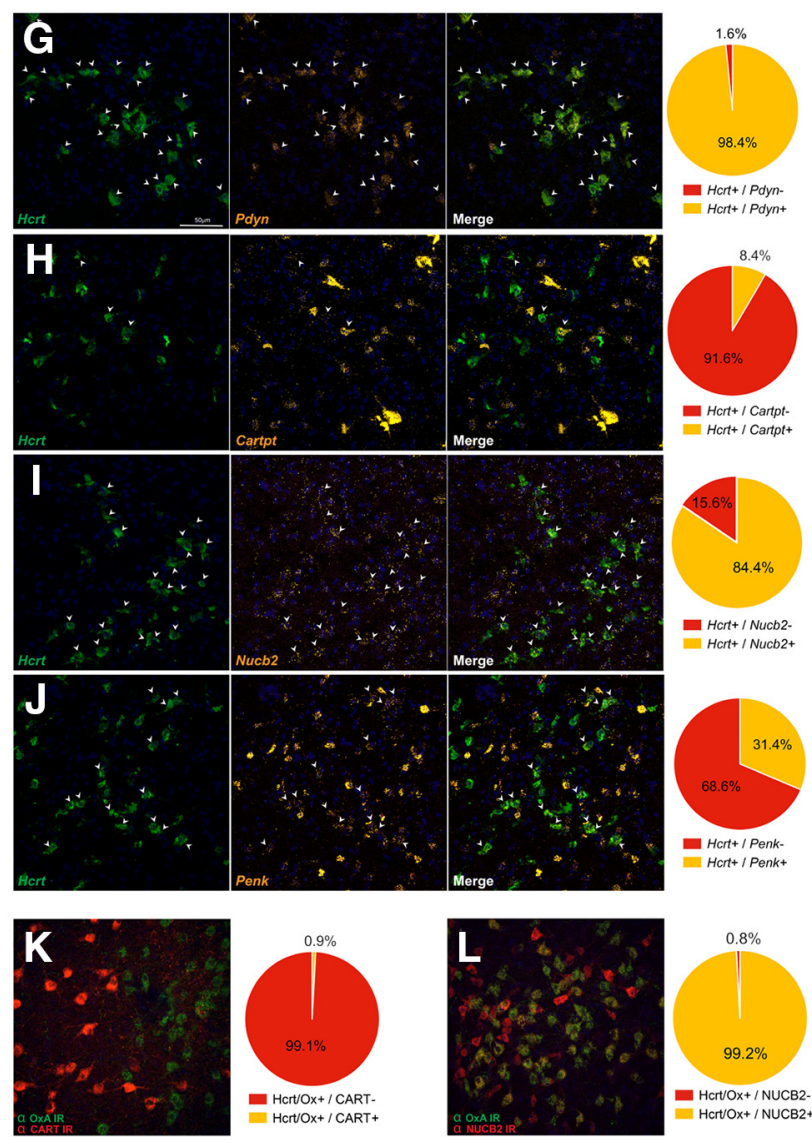

Figure 6. In situ hybridization and immunohistochemical validation of neuropeptide expression in $\mathrm{Hcrt} / \mathrm{Ox}$ and $\mathrm{MCH}$ neurons. $\boldsymbol{A}-\boldsymbol{D}$ Confocal micrographs $(40 \times)$ of coronal sections from wild type mice and corresponding pie charts representing coexpression of mRNA for Pmch and Pdyn, $n=47$ cells (A), Pmch and Cartpt, $n=190$ cells (B), Pmch and Nucb2, $n=77$ cells $(\boldsymbol{C})$, and Pmch and Penk, $n=75$ cells $(\boldsymbol{D})$; all counterstained with DAPI (blue). White arrows indicate coexpression. $\boldsymbol{E}, \boldsymbol{F}$, Confocal micrographs (40 $\times$ ) of coronal sections from Pmch-cre;EYFP mice counterstained for anti-GFP (green), anti-CART (red), $n=134$ cells (E), and anti-NUCB2 (red), $n=134(\boldsymbol{F})$; all counterstained for DAPI (blue). G-J, Confocal micrographs $(40 \times)$ of coronal sections from wild type mice and corresponding pie charts representing coexpression of mRNA for Hcrt and Pdyn, $n=125$ cells (G), Hcrt and Cartpt, $n=154$ cells $(\boldsymbol{H})$, Hcrt and Nucb2, $n=90$ cells (I), and Hcrt and Penk, $n=169$ cells (J); all counterstained with DAPI (blue). White arrows indicate coexpression. $\boldsymbol{K}, \boldsymbol{L}$, Confocal micrographs $(40 \times)$ of coronal sections from wild type mice counterstained for anti-OxA (green) and anti-CART (red), $n=115(\boldsymbol{K})$, and anti-NUCB2 (red), $n=115(\boldsymbol{M})$; all counterstained with DAPI (blue).

our single-cell qPCR analysis of Pdyn, Cartpt, Nucb2, and Penk in Hcrt/Ox and MCH neurons within the LHA.

\section{Hcrt/Ox and MCH neurons exhibit markers of both GABAergic and glutamatergic fast neurotransmitter phenotypes}

While $\mathrm{MCH}$ and Hcrt/Ox neurons are widely thought to exhibit GABAergic and glutamatergic phenotypes, respectively, recent evidence suggests greater ambiguity in their fast neurotransmitter phenotype than previously appreciated (Bonnavion et al., 2016). To address this conflicting evidence using our single-cell GPCR dataset, we compared the expression patterns of genes necessary for fast amino acid neurotransmitter synthesis and vesicular transport among $\mathrm{MCH}$ (Fig. $7 A$ ) and Hcrt/Ox neurons (Fig. $7 B$ ) and summarized their differential expression in the form of bubble plots (Fig. 7E).

Consistent with the widely held view that $\mathrm{MCH}$ neurons are GABAergic in nature, we found that virtually all $\mathrm{MCH}$ neurons express the GABA synthetic enzyme Gad1
(97.8\%) and a smaller subpopulation expresses Gad2 (21.3\%; Fig. 7; Table 2). However, none of the $\mathrm{MCH}$ neurons exhibited detectable expression of the vesicular GABA transporter S/c32a1 (0\%) This suggests that while these cells may be capable of GABA synthesis, they lack the machinery for its vesicular packaging and release through canonical pathways. In contrast, the vesicular glutamate transporter 2 (S/c17a6) was expressed in virtually every $\mathrm{MCH}$ neuron (97.8\%) with a very small subpopulation of neurons expressing the vesicular glutamate transporter 3, S/c17a8 (9.0\%; Fig. 7A), suggesting a functional glutamatergic phenotype. Similarly, we found that every Hcrt/Ox neuron expressed S/c17a6 (100\%) approximately half of which also express S/c17a8 (47.8\%; Fig. 7; Table 2), consistent with evidence showing that these cells are glutamatergic. Surprisingly, over half of the Hcrt/Ox neurons we sampled expressed Gad1 (56.5\%) and a smaller subpopulation expressed Gad2 (15.9\%). As with $\mathrm{MCH}$ neurons, we found that S/c32a1 expression was virtually undetectable in Hcrt/Ox neurons (1.5\%). Finally, S/c17a7 


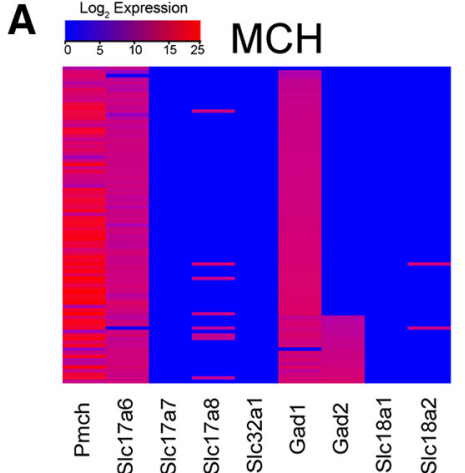

C

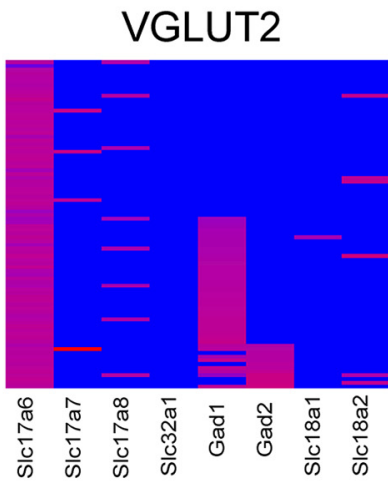

B

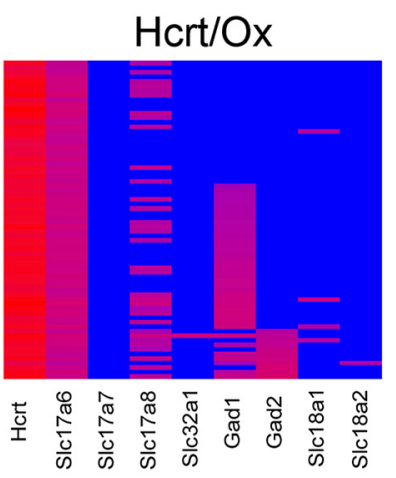

D

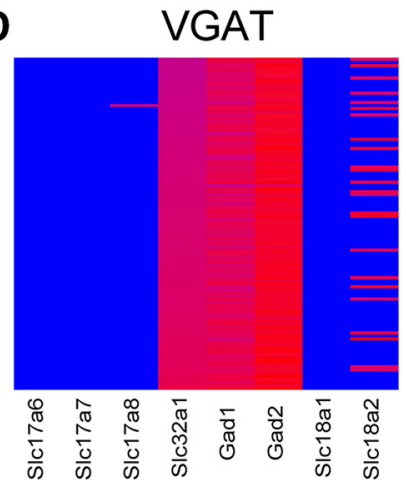

E

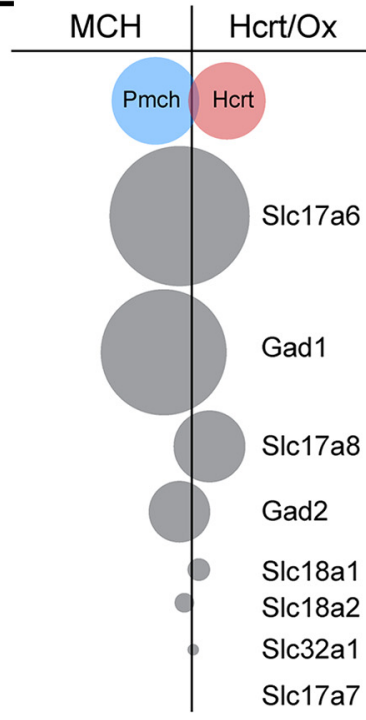

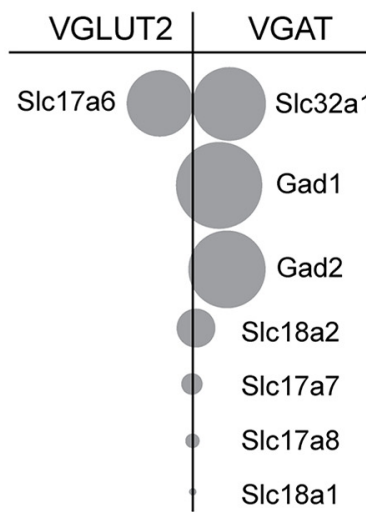

Slc18a1

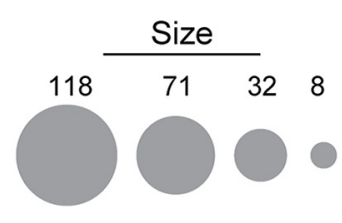

Figure 7. Analysis of fast amino acid neurotransmitter phenotypes. A, B, Manually ordered heatmaps of neurotransmitter expression in $\mathrm{MCH}(\boldsymbol{A})$ and Hcrt/Ox $(\boldsymbol{B})$ neurons, arranged by function in glutamatergic or GABAergic release pathways. $\boldsymbol{C}, \boldsymbol{D}$, Manually ordered heatmaps of neurotransmitter expression in VGLUT2+ $(\boldsymbol{C})$ and VGAT+ $(\boldsymbol{D})$ neurons isolated from Vglut2-Cre;EYFP and Vgat-Cre;EYFP mice, respectively, arranged by function in glutamatergic or GABAergic release pathways. $\boldsymbol{E}$, Bubble plot depicts the net difference of detection in expression frequency of the neurotransmitter component indicated. Left, Neurotransmitters with higher frequency of detection in $\mathrm{MCH}$ neurons are to the left of the black line, higher frequency in Hcrt/Ox neurons to the right. Right, Neurotransmitters with higher frequency of detection in VGLUT2 neurons are to the left of the black line, higher frequency in VGAT neurons to the right.

expression was undetectable in either population. Given the abundant expression of Gad1 in both populations, and failure to detect S/c32a1, we asked whether Hcrt/Ox and $\mathrm{MCH}$ neurons expressed the vesicular monoamine transporters S/c18a1 and S/c18a2, the latter of which has been shown to be capable of the transport and vesicular release of GABA through a noncanonical pathway (Tritsch et al., 2012). We found, however, that only a very small fraction of $\mathrm{MCH}$ (2.5\%) and Hcrt/Ox (1.5\%) neurons express S/c18a2 transcript at detectable levels.

Having observed the surprising result that these two populations of neuropeptidergic neurons in the LHA uniformly and abundantly express the machinery for both glutamate release (S/c17a6) and GABA synthesis (Gad1), we asked if this pattern of coexpression is a common feature of glutamatergic neurons in the LHA. To this end, we performed an identical single-cell qPCR analysis of S/c17a6-expressing LHA neurons from Vglut2-Cre;EYFP mice. As these mutant mice label cells with both transient developmental and stable expression of S/c17a6, we isolated 117 single labeled neurons from microdissected slices that passed Gapdh prescreening and confined our analysis to the 86 neurons expressing the S/c17a6 transcript (73.5\%). Of these cells, none expressed S/c32a1 (0\%; 0/86; Fig. 7C). However, exactly half of these S/c17a6-expressing neurons expressed Gad1 (50\%; 43/86) along with another small, partially overlapping population expressing Gad2 (14.0\%; 12/86). Although the sample size is limited, these data suggest that approximately half of S/c17a6-expressing, putative glutamatergic neurons in the LHA are potentially capable of GABA synthesis.

Finally, considering that in our analysis of Hcrt/Ox, $\mathrm{MCH}$ and glutamatergic neurons, we did not detect expression of S/c32a1, we asked whether this was the result of a true lack of expression or the failure of our probe to detect S/c32a1 expression. Furthermore, we wished to confirm the neurotransmitter phenotype of canonical GABAergic neurons in the LHA (i.e., those capable of both the synthesis and vesicular release of GABA). For this purpose, we performed a single-cell GPCR analysis of S/c32a1-expressing neurons from the LHA of Vgat-Cre; EYFP mice. Similar to the Vglut2-expressing cells collected above, we isolated 212 single neurons and focused our analysis on the 118 cells expressing the S/c32a1 transcript $(55.7 \%)$. We found that virtually none of these cells expressed vesicular glutamate transporters (S/c17a6: 0\%; 0/118, S/c17a7: 0\%; 0/118, S/c17a8: 0.8\%; 1/118). However, all S/c32a1-expressing neurons robustly and uniformly expressed the triad of canonical markers of GABAergic phenotype (S/c32a1: 100\%; 118/118, Gad1: 100\%; 118/118, Gad2: 100\%; 118/118). These data confirm that we can detect S/c32a1 in GABAergic neurons and that LHA GABAergic neurons uniformly and abun- 

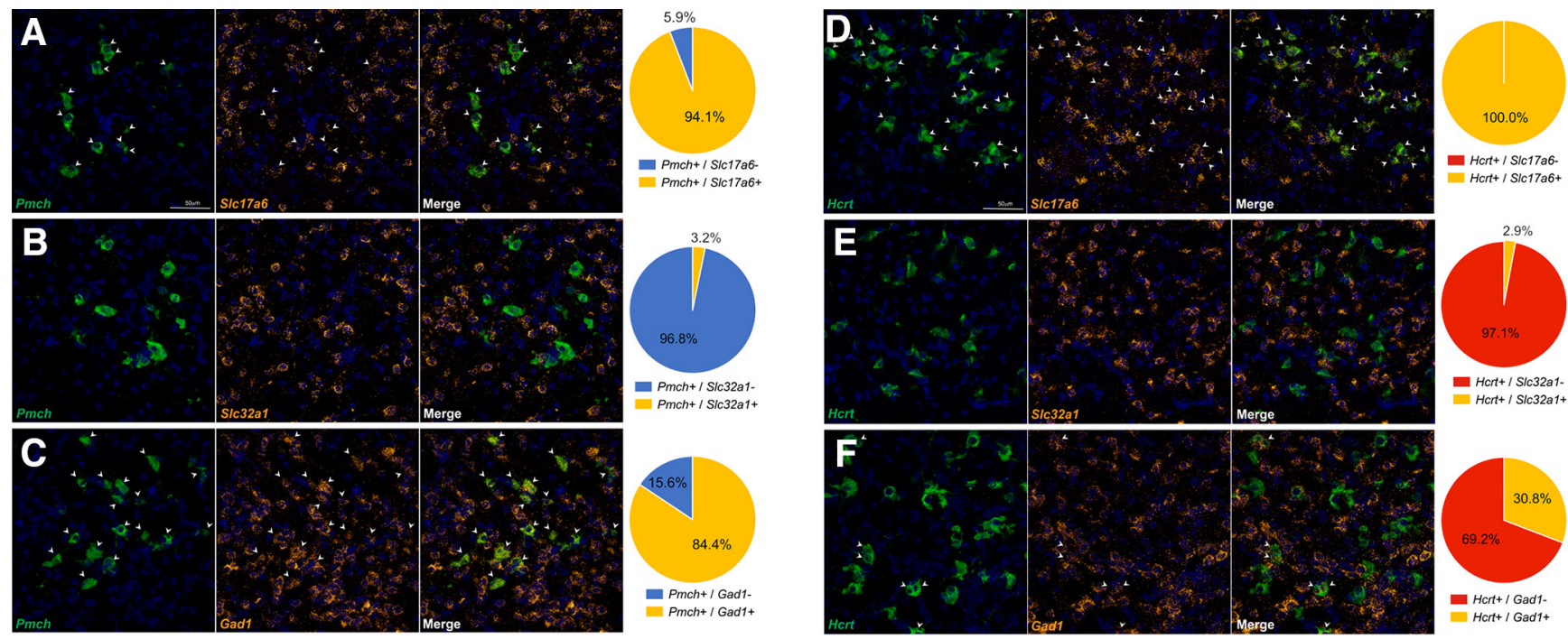

Figure 8. In situ hybridization validation of fast amino acid neurotransmitter expression in Hcrt/Ox and MCH neurons. $\boldsymbol{A}-\mathbf{C}, \mathrm{Confocal}$ micrographs $(40 \times)$ of coronal sections from wild type mice and corresponding pie charts representing coexpression of mRNA for Pmch and Slc17a6, $n=51$ cells $(\boldsymbol{A})$, Pmch and Slc32a1, $n=63$ cells $(\boldsymbol{B})$, and Pmch and Gad1, $n=224$ cells $(\boldsymbol{C})$; all sections counterstained with DAPI (blue). $\boldsymbol{D}-\boldsymbol{F}$, Confocal micrographs $(40 \times)$ of coronal sections from wild type mice and corresponding pie charts representing coexpression of mRNA for Hcrt and Slc17a6, $n=45$ cells (D), Hcrt and S/c32a1, $n=170$ cells (E), and Hcrt and Gad1, $n=237(\boldsymbol{F})$; all sections counterstained with DAPI (blue). White arrows indicate coexpression.

dantly express markers of canonical GABA synthesis and release (S/c32a1, Gad1, and Gad2).

\section{In situ hybridization validation of fast amino acid neurotransmitter marker expression in Hcrt/Ox and $\mathrm{MCH}$ neurons}

To validate the expression of S/c17a6 and Gad1, as well as the absence of S/c32a1, in Hcrt/Ox and $\mathrm{MCH}$ neurons we again used FISH analysis (Fig. $8 A-F$ ). We confirmed extensive overlap of $\mathrm{MCH}$ (48/51 cells; $94.1 \%)$ and complete overlap of Hcrt/Ox (45/45 cells; $100 \%)$ neurons with Slc17a6 mRNA (Fig. 8A,D), with minimal colocalization of Slc32a1 mRNA with $\mathrm{MCH}$ neurons (2/63 cells; $3.2 \%)$ and Hcrt/Ox (5/170 cells; 2.9\%; Fig. 8B,E). Furthermore, we found that $84.4 \%(189 / 224)$ of $\mathrm{MCH}$ neurons colocalized with Gad1 mRNA (Fig. 8C) while approximately $30.8 \%$ (73/237) of Hcrt/Ox neurons contained Gad1 mRNA (Fig. $8 F$ ). These data are broadly consistent with our single-cell qPCR analysis of S/c17a6, Gad1, and S/c32a1 in Hcrt/Ox and $\mathrm{MCH}$ neurons within the LHA.

\section{Comparing electrophysiological diversity with neurochemical diversity in Hcrt/Ox neurons}

Finally, we asked whether the neurochemical heterogeneity that we identified among Hcrt/Ox and $\mathrm{MCH}$ neurons correlates with known functional diversity. To approach this question, we turned to the well-characterized intrinsic membrane properties of Hcrt/Ox neurons.

Previous work in brain slices from Ox-EGFP mice has shown that, on the basis of key intrinsic membrane properties, morphologic characteristics and measures of synaptic input, Hcrt/Ox neurons may be parsed into two functional subpopulations (Schöne et al., 2011). In particular, Schöne and coauthors found that the signature of one population ("D-type") is a depolarizing rebound in firing following a hyperpolarizing step in current-clamp mode. Another population ("H-type"), in turn, exhibited a characteristic long latency to firing following the same hyperpolarizing step as a result of prominent expression of A-type potassium current (Burdakov et al., 2004; Schöne et al., 2011). Neither population was shown to segregate on the basis of their projection targets (González et al., 2012). We asked whether we could (1) recapitulate this broad categorization; (2) harvest cytoplasm from recorded cells for qPCR analysis using the same 48-gene panel and correlate gene expression with FACS-sorted cells; and (3) determine if D-type and $\mathrm{H}$-type signatures segregated between neurochemically distinct Hcrt/Ox neurons at the single-cell level. For example, can Gad1+ and Gad1- Hcrt/Ox neurons be identified on the basis of key electrical signatures?

We obtained slices from Ox-EGFP mice and performed patch-clamp recordings from $16 \mathrm{EGFP}+$ neurons. From current-clamp recordings, we found that $62.5 \%(10 / 16)$ Hcrt/Ox neurons exhibited a depolarizing postinhibitory rebound following a $1 \mathrm{~s}$ hyperpolarizing step, consistent with the D-type signature. In turn, 37.5\% (6/16) Hcrt/Ox neurons exhibited a latency (>100 ms) to firing following the hyperpolarizing step, consistent with the $\mathrm{H}$-type signature (Fig. $9 A, B$ ). We also noted the location of each recorded cell and mapped them onto an atlas image of the LHA (Fig. 9C). We then harvested cytoplasm from each of these neurons through the recording pipette and performed single-cell qPCR analysis using our 48-gene panel, in an otherwise identical manner to FACS-sorted cells. We found that $93.7 \%(15 / 16)$ of these Hcrt/Ox neurons expressed Hcrt in addition to other key discriminatory genes known to be enriched in Hcrt/Ox neurons including Lhx9, Nptx2, Pdyn, and Nnat. In performing unsupervised hierarchical clustering of the gene expres- 
A
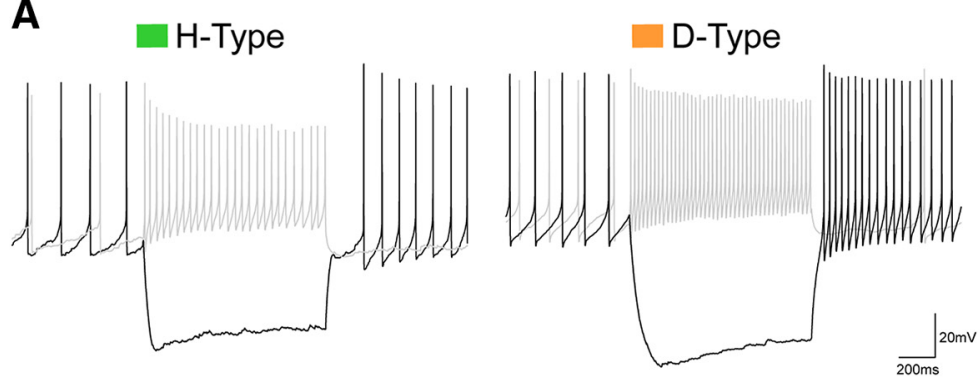

D

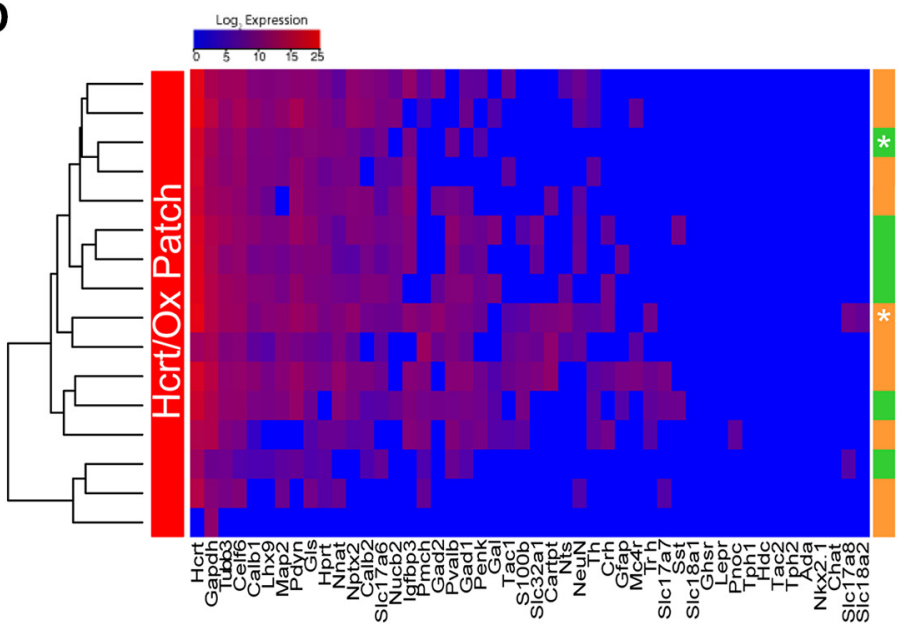

B

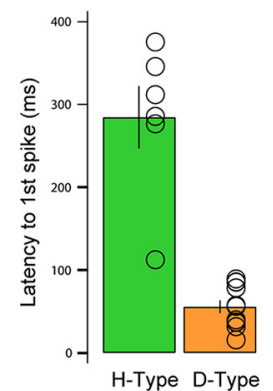

C

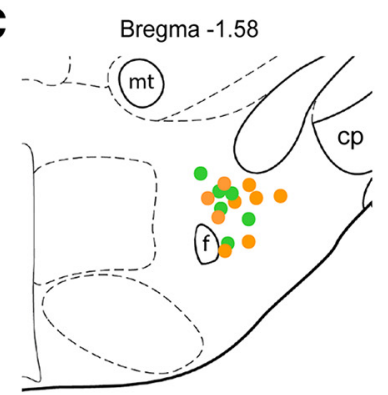

E

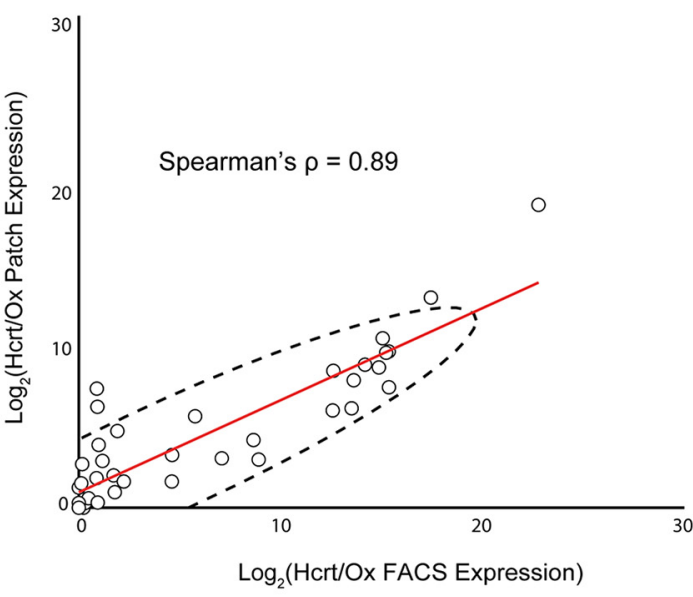

Figure 9. Manual (patch) harvest of mRNA from Hcrt/Ox neurons and correlation between neurochemcial phenotype and membrane properties. A, Representative current-clamp recordings of two Hcrt/Ox neurons responding to +40 pA (gray) and -40 pA (black) current injections, identifying $\mathrm{H}$-type (left) and D-type (right) signatures. In all panels, green denotes $\mathrm{H}$-type while orange denotes D-type. B, Latency to first spike after a 1 s hyperpolarizing step of -120 pA, threshold for H-type set at $100 \mathrm{~ms}(n=16 \mathrm{cells} ; 6 \mathrm{H}$-type, 10 D-type). C, Schematic of a representative LHA slice with the approximate location of recorded H-type and D-type Hcrt/Ox neurons. $D$, Unsupervised hierarchical clustering heatmap of $16 \mathrm{Hcrt} / O x$ neurons measured for the expression of 48 genes by qPCR, along with their electrical signature. Asterisks indicate the two individual cells corresponding to traces in $\boldsymbol{A}$. $\boldsymbol{E}$, Scatterplot showing expression of all 48 genes measured in both our single-cell Hcrt/Ox qPCR dataset ( $x$-axis) and patch harvested Hcrt/Ox qPCR dataset $(y$-axis). The two datasets show strong correlation (Spearman's $\rho=0.89 ; p=2.2 \times 10^{-16}$ ).

sion data, we failed to detect a clear correlation between neurochemically diverse Hcrt/Ox neurons and electrophysiological signatures (Fig. 9D). Despite this, when we compared gene expression patterns between recorded cells and FACS-sorted cells, we found a strong, positive linear correlation with a Spearman's correlation coefficient $\rho=0.89\left(\rho=2.2 \times 10^{-16}\right.$; Fig. $\left.9 E\right)$. Taken together, these data suggest that although distinct electrical signatures of Hcrt/Ox neurons may not readily track with the known markers of neurochemical phenotype included in our gene panel, the gene expression profile of manually harvested single neurons, that have undergone whole-cell recordings, closely match FACSsorted single cells.

\section{Discussion}

Underlying functionally discrete neuronal cell types in the brain are suites of differentially expressed genes that determine and maintain cell type identity (Nelson et al., 2006; Fishell and Heintz, 2013). An important category of these discriminatory genes are those that specify neurochemical phenotype, i.e. the expression of neuropeptides and markers of cholinergic, monoaminergic, purinergic and fast amino acid neurotransmission. In the hypothalamus, neuronal populations are often defined by their expression of neuropeptides, but an ever growing body of molecular, anatomic and functional evidence suggests that many hypothalamic neuronal cell types are equipped with a broader palette of neurochemical signaling mechanisms that may include multiple neuropeptides and fast neurotransmitters (Schöne and Burdakov, 2012; van den Pol, 2012; Arrigoni and Saper, 2014; Bonnavion et al., 2016). In the LHA, mounting evidence suggests that $\mathrm{Hcrt} / \mathrm{Ox}$ and $\mathrm{MCH}$ neurons exhibit a complex but poorly understood repertoire of neuropeptide and fast neurotransmitter signaling mechanisms (Bonnavion et al., 2016). We undertook a quantitative single-cell gene expression profiling approach to better understand the neurochemical phenotype of Hcrt/Ox and $\mathrm{MCH}$ neurons. We optimized a robust procedure for microdissecting the LHA from transgenically-labeled mouse lines, cleanly isolating single Hcrt/Ox and $\mathrm{MCH}$ neurons via FACS and quantifying the expression of a panel of 48 genes in each cell to define neurochemical phenotype. We found that, in addition to expressing a number of neuropeptide transcripts, 
all $\mathrm{MCH}$ and a subpopulation of Hcrt/Ox neurons express markers for both inhibitory and excitatory fast neurotransmission. Furthermore, we found this profile is characteristic of a subpopulation of LHA glutamatergic neurons, but contrasts with a broad population of LHA GABAergic neurons. Finally, we found that electrical signatures that define Hcrt/Ox subpopulations do not appear to track with neurochemical phenotype.

\section{Comparison with previous approaches, technical considerations, and limitations}

Previous studies of single-cell expression profiling in rodents were performed in rats; one probing the expression of five genes in manually harvested cells labeled with antibodies (Volgin et al., 2004) and another examining twelve genes from cells in fixed tissue, isolated using laser capture microdissection (LCM; Harthoorn et al., 2005). Two recent reports, however, describe single-cell microarray analysis (Liu et al., 2015) and RNA sequencing (Yelin-Bekerman et al., 2015) of zebrafish Hcrt neurons, which exhibit conserved function and expression of the key transcription factor gene $L h \times 9$. Nevertheless, our approach represents an improvement over previous singlecell methods in the rodent LHA in terms of scale, throughput and precision. Furthermore, LCM has been shown to be significantly more prone to contamination, from glial cells in particular, as compared to FACS-sorted cells (Okaty et al., 2011). We found that robust expression of neuronal markers, with little to no expression of glial markers in these samples, was evidence for minimal contamination by glial cells. Furthermore, our failure to detect significant signal from single, fluorescent, FACS-sorted beads that were intermixed with our cell suspensions was evidence for minimal contamination by ambient transcripts in the media. With respect to the specificity of single-cell capture, we found that the vast majority of $\mathrm{Hcrt} / \mathrm{Ox}$ and $\mathrm{MCH}$ neurons exhibited highly specific expression of their respective neuropeptides consistent with our demonstration that key transcription factor genes Lhx9 and Nkx2.1 exhibited selective and mutually exclusive expression.

However, the interpretation of our single-cell gene expression analysis must be considered in light of several important caveats. One is the specificity and penetrance of the mutant mouse lines that we used. Despite the presence of EYFP potentially reflecting both transient developmental and stable Pmch promoter-driven cre expression, Pmch-Cre;EYFP mice are very effective in selectively labeling Pmch-expressing neurons and capturing a large percentage of the $\mathrm{MCH}-\mathrm{IR}$ population. Although Ox-EGFP mice show high specificity, the penetrance of their EGFP expression is comparatively low and we captured only about half of the Hcrt/Ox-IR population. Whether this represents a random cross-section of the Hcrt/Ox population or a specific, molecularly-defined subpopulation remains to be determined. Nevertheless, in each case, we independently assessed $\mathrm{Hcrt} / \mathrm{Ox}$ or $\mathrm{MCH}$ expression through qPCR as an internal control to account for any lack of specificity of the transgenic line. Furthermore, the neurochemical profile of Hcrt/Ox neu- rons, that we determined through single-cell analysis, closely matched bulk RNA-TRAP data derived from another transgenic reporter with higher penetrance (Dalal et al., 2013; Fig. 4).

Another set of technical considerations in the interpretation of this data include: (1) the age and gender of the mice; (2) circadian, metabolic and behavioral state; (3) sample size; and (4) detection of mRNA as a reflection of translated protein. With regard to age, we chose to collect neurons from juvenile mice (P21-P23) to approximate baseline gene expression patterns in adult mice yet optimize the isolation of healthy and intact neurons following FACS sorting, which we found to be compromised in older animals. Although we chose to limit our study to males, future work comparing male and female mice will be required to probe possible sexual dimorphism in gene expression. In another effort to limit variability and obtain an approximation of baseline gene expression, we collected cells from mice at the same time of day in the absence of metabolic or behavioral challenges, which likely alters gene expression in LHA neurons (Leibowitz, 2007; Barson et al., 2013). Our qPCR and FISH data may be considered a snapshot of gene expression in juvenile male mice under these baseline conditions. With regard to sample size, we found that the number of single cells that we collected, along with minimal between-batch variability, had sufficient statistical power to detect even moderate levels of differential gene expression. However, further work, ideally employing whole transcriptome analysis of a large number of single neurons would be required to allow a higher resolution interrogation of neurochemical heterogeneity among these neurons. A final caveat in interpreting our single-cell qPCR data, as with any gene expression data, is that quantifying mRNA content with high sensitivity may or may not be a faithful, linear representation of translated protein (Citri et al., 2011). Also, given the stochastic nature of gene expression in single cells (Raj and van Oudenaarden, 2008), there may be an element of noise in the gene expression patterns that we observe, the extent to which, and biological significance of, remains to be determined.

\section{Neuropeptide/receptor coexpression in Hcrt/Ox and $\mathrm{MCH}$ neurons}

Single $\mathrm{MCH}$ and Hcrt/Ox neurons express a variety of neuropeptide transcripts including some with clear differential expression. Hcrt/Ox neurons exhibit robust and selective expression of Pdyn, as shown previously (Chou et al., 2001; Muschamp et al., 2014), and moderately specific expression of Penk. MCH neurons, in turn, showed moderately specific expression of Cartpt, with apparent Pmch+ populations that were either Cartpt + or Cartpt-, consistent with previous work (Broberger, 1999; Vrang et al., 1999; Brischoux et al., 2001; Elias et al., 2001; Cvetkovic et al., 2004), although we found more expression in Hcrt/Ox neurons than expected. Other transcripts (Nucb2 and $\mathrm{Gal}$ ) exhibit surprisingly abundant expression among the two populations. Previous studies showed strong colocalization between NUCB2-IR and $\mathrm{MCH}-\mathrm{IR}$ but not with Hcrt/Ox-IR (Foo et al., 2008; Fort et al., 2008). 
While GAL-IR has been observed in Hcrt/Ox neurons (Håkansson et al., 1999), subsequent work showed no coexpression in Hcrt/Ox or $\mathrm{MCH}$ neurons (Laque et al., 2013). Despite the heterogeneity in neuropeptide transcript expression, clear subpopulations did not emerge from our unsupervised cluster analysis. Further work is required to determine if neuropeptide coexpression, or a constellation of other key markers, may be the primary driver(s) of population diversity among these and other LHA neurons.

Nevertheless, $\mathrm{MCH}$ and Hcrt/Ox neurons likely have the capacity to release multiple neuropeptides, evidenced by neuropeptide colocalization in single terminals (Guan et al., 2002; Balcita-Pedicino and Sesack, 2007) or even in the same dense-core vesicle (Muschamp et al., 2014). Furthermore, the release of multiple neuropeptides may significantly impact the ability of single neurons to tune their postsynaptic targets (van den Pol, 2012). For example, Hcrt/Ox and dynorphin cotransmission has been proposed to differentially regulate postsynaptic excitability among target neurons (Li and van den Pol, 2006; Arrigoni et al., 2010; Muschamp et al., 2014; Ferrari et al., 2015). Although Hcrt/Ox release from Hcrt/Ox fibers has been demonstrated using an optogenetic approach (Schöne et al., 2014), evoked release of multiple neuropeptides, and determining their role in circuit function, remains a significant technical challenge (van den Pol, 2012; Arrigoni and Saper, 2014).

\section{Fast neurotransmitter coexpression in $\mathrm{MCH}$ and Hcrt/Ox neurons}

$\mathrm{MCH}$ neurons have long been thought to exhibit a GABAergic phenotype, evidenced by their expression of GABAergic markers such as GAD1 mRNA (Elias et al., 2001; Harthoorn et al., 2005; Sapin et al., 2010). Immunohistochemical evidence has shown that a small proportion of $\mathrm{MCH}+$ varicosities found in the locus coeruleus (LC) contain VGAT and another small proportion oppose gephryin puncta on $\mathrm{TH}+$ cell bodies (del Cid-Pellitero and Jones, 2012), suggesting the capacity of at least a small proportion of $\mathrm{MCH}$ neurons for synaptic GABA release. Consistent with these findings, optogenetic experiments showed that selective stimulation of $\mathrm{MCH}$ fibers evoked GABA release onto hypothalamic histaminergic (HA) neurons in brain slices (Jego et al., 2013). However, further work showed that $\mathrm{MCH}$ neurons may not fit the profile of canonical GABAergic neurons. First, $\mathrm{MCH}$-IR was shown not to overlap with intermingled VGAT-expressing LHA neurons in Vgat-Cre;EYFP mice (Jennings et al., 2015). Furthermore, recent work shows that the vast majority of $\mathrm{MCH}$ neurons express mRNA for VGLUT2 while virtually none express VGAT, and that optogenetic activation of $\mathrm{MCH}$ fibers in the lateral septum induces monosynaptic release of glutamate, not GABA (Chee et al., 2015). The most parsimonious interpretation of our single-cell results is that $\mathrm{MCH}$ neurons are functionally glutamatergic $(S / c 17 a 6+)$ and uniformly capable of GABA synthesis $(\mathrm{Gad} 1+)$, but that GABA release (S/c32a1-) is either mostly nonsynaptic or occurs through a noncanonical pathway as discussed further in the next section.
Convincing anatomic evidence suggests that Hcrt/Ox neurons are glutamatergic (Horvath et al., 1999; Guan et al., 2002; Rosin et al., 2003; Torrealba et al., 2003; Balcita-Pedicino and Sesack, 2007) including immunohistochemical evidence that a small proportion of Hcrt/Ox+ varicosities in the LC contain VGLUT2 and another small percentage oppose postsynaptic density protein-95 (PSD-95) puncta (Henny et al., 2010). Furthermore, optogenetic stimulation of Hcrt/Ox fibers induced glutamate release onto HA neurons (Schöne et al., 2012). As with $\mathrm{MCH}$ neurons, other data suggest ambiguity regarding the fast neurotransmitter phenotype of Hcrt/Ox neurons. Ultrastructural data in rats shows that while a majority of Hcrt/Ox terminals have asymmetric synapses, symmetric synapses are also present (Guan et al., 2002; Torrealba et al., 2003; Balcita-Pedicino and Sesack, 2007). Furthermore, recent work demonstrated that optogenetic activation of Hcrt/Ox neurons suppresses firing in nearby $\mathrm{MCH}$ neurons through light-evoked inhibitory synaptic events, which in some cases were time-locked to the stimulus with relatively short latencies, abolished by gabazine, but unaffected by glutamate receptor blockade. Although this may be explained by a disynaptic mechanism, GABA-IR was found in $\sim 10-20 \%$ of Hcrt/Ox-IR neurons (ApergisSchoute et al., 2015). Our single-cell qPCR data are broadly consistent with the notion that Hcrt/Ox neurons are functionally glutamatergic $(S / c 17 a 6+)$, and that a subpopulation $(\sim 50 \%)$ are potentially capable of GABA synthesis $(\mathrm{Gad} 1+)$, but not release through a canonical pathway (S/c32a1-).

\section{Implications for neurochemical flexibility and plasticity among $\mathrm{MCH}$ and $\mathrm{Hcrt} / \mathrm{Ox}$ neurons}

We found that virtually all $\mathrm{MCH}$ neurons and approximately half of Hcrt/Ox neurons exhibit mixed fast neurotransmitter profiles (S/c17a6+, S/c32a1-, Gad1+). We also showed that this profile is characteristic of the broader population of LHA VGLUT2 neurons, half of which are Gad1+, suggesting that Gad1 expression may not be a reliable marker for GABAergic phenotypes in this region. Formally, one explanation is that both $\mathrm{MCH}$ and Hcrt/Ox neuron populations have a functionally glutamatergic phenotype (S/c17a6+, S/c32a1-). Alternatively, given the prominent expression of Gad1 among these neurons, it is tempting to speculate that $\mathrm{MCH}$ neurons and a subpopulation of Hcrt/Ox neurons may be capable of glutamate/ GABA cotransmission through noncanonical GABA release pathways described in other systems (Seal and Edwards, 2006; Hnasko and Edwards, 2012; Münster-Wandowski et al., 2013; Barker et al., 2016; Tritsch et al., 2016; Granger et al., 2017). Anatomic and functional evidence for glutamate/GABA corelease from single neurons has been described in the developing auditory brainstem and among hippocampal mossy fibers during development and in the adult (Seal and Edwards, 2006; Hnasko and Edwards, 2012; Münster-Wandowski et al., 2013). Recent reports describe functional, monosynaptic glutamate/ GABA cotransmission in basal ganglia outputs to the lateral habenula (LHb), with VGLUT2-IR and GAD-IR colocalized in terminals, as well as evidence that VGAT is 
necessary for cotransmission (Shabel et al., 2014). In addition, evidence for glutamate/GABA cotransmission was shown in two recent studies of ventral tegmental area (VTA) projections. In one, VGLUT2, VGAT and GAD appear to colocalize in single mesohabenular axons to facilitate glutamate/GABA corelease (Root et al., 2014). In the other, VGLUT2 + VTA neurons exhibit target-dependent monosynaptic cotransmission, with glutamate/GABA corelease in the $\mathrm{LHb}$, but exclusive glutamate release in the nucleus accumbens (Yoo et al., 2016). In these latter cases, glutamate/GABA cotransmission appears to depend on colocalization of VGLUT2 and VGAT. However, among $\mathrm{MCH}$ and Hcrt/Ox neurons, S/c32a1 mRNA was undetectable in our qPCR analysis and minimal in our $\mathrm{FISH}$ analysis. If $\mathrm{MCH}$ and a subset of Hcrt/Ox neurons are indeed capable of synaptic GABA corelease, it may occur through an alternative pathway. Noncanonical vesicular GABA release through VMAT2 (Tritsch et al., 2012) is an unlikely candidate in this case as S/c18a2 is virtually undetectable among $\mathrm{Hcrt} / \mathrm{Ox}$ and $\mathrm{MCH}$ neurons. Another alternative pathway is through reversal of the plasma membrane GABA transporter GAT-1 (Wu et al., 2007), which remains to be investigated. Finally, highly informative recent single-cell RNA sequencing studies of neuronal populations in the medial hypothalamus (Romanov et al., 2017; Campbell et al., 2017) and entopenduncular nucleus of the basal ganglia (Wallace et al., 2017) have revealed compelling evidence for mixed fast neurotransmitter gene expression profiles, suggesting that such forms of cotransmission may be more common than previously thought.

Regarding the Gad1+, S/c32a1- profile of $\mathrm{MCH}$ and Hcrt/Ox neurons, an informative comparison may be made with proopiomelanocortin (POMC) neurons in the arcuate nucleus. Detailed anatomic, electrophysiological and optogenetic analysis of the neurochemical phenotype of POMC neurons by Hentges and coworkers has revealed that this neuronal population may be parsed into two functional subpopulations: GABAergic (Gad1+ and/or Gad2+), and a much smaller population of glutamatergic POMC neurons (S/c17a6+), half of which also express Gad2 (Hentges et al., 2004, 2009; Jarvie and Hentges, 2012). Interestingly, POMC GABAergic neurons are capable of fast synaptic release of GABA (Hentges et al., 2009; Dicken et al., 2012) yet S/c32a1 is virtually undetectable (Jarvie and Hentges, 2012), but may be expressed in small subpopulations (Jeong et al., 2016). Nevertheless, this suggests that GABA may largely be released from these cells through a noncanonical pathway. These same phenotypic markers were shown to change over postnatal development (Dennison et al., 2016) and can shift following metabolic perturbation (Dicken et al., 2015; Jarvie et al., 2017). Given evidence of alterations in neuropeptide gene expression in the LHA following metabolic and behavioral challenges (Leibowitz, 2007; Barson et al., 2013) and neurochemical phenotype switching in other systems (Demarque and Spitzer, 2012), it is plausible that $\mathrm{MCH}$ and Hcrt/Ox neurons also have the capacity for dynamic expression of key genes that specify neurochemical profile.
The possibility that $\mathrm{MCH}$ and/or Hcrt/Ox neurons exhibit neuropeptidergic and glutamate/GABA cotransmission, target-dependent cotransmission or the capacity for plasticity in neurotransmitter phenotype following metabolic or behavioral challenges all remain intriguing questions. Furthermore, the mechanisms of cotransmission and neurochemical heterogeneity may be the basis for functional classification of neuronal cell types in the LHA, as well as an important means of understanding their role in regulating postsynaptic excitability. Overall, our singlecell qPCR analysis of $\mathrm{MCH}$ and Hcrt/Ox neurons suggests the capacity for neurochemical flexibility: the ability to draw on a broad palette of signaling mechanisms with which to rapidly respond to fluctuating intrinsic and extrinsic physiologic challenges.

\section{References}

Abrahamson EE, Moore RY (2001) The posterior hypothalamic area: chemoarchitecture and afferent connections. Brain Res 889:1-22. Medline

Adamantidis AR, Zhang F, Aravanis AM, Deisseroth K, de Lecea L (2007) Neural substrates of awakening probed with optogenetic control of hypocretin neurons. Nature 450:420-424. CrossRef Medline

Agresti A (1992) A survey of exact inference for contingency tables. Stat Sci 7:131-153. CrossRef

Alexandre C, Andermann ML, Scammell TE (2013) Control of arousal by the orexin neurons. Curr Opin Neurobiol 23:752-759. CrossRef Medline

Apergis-Schoute J, lordanidou P, Faure C, Jego S, Schöne C, AittaAho T, Adamantidis A, Burdakov D (2015) Optogenetic Evidence for Inhibitory Signaling from Orexin to $\mathrm{MCH}$ Neurons via Local Microcircuits. J Neurosci 35:5435-5441. CrossRef Medline

Arrigoni E, Saper CB (2014) What optogenetic stimulation is telling us (and failing to tell us) about fast neurotransmitters and neuromodulators in brain circuits for wake-sleep regulation. Curr Opin Neurobiol 29:165-171. CrossRef Medline

Arrigoni E, Mochizuki T, Scammell TE (2010) Activation of the basal forebrain by the orexin/hypocretin neurones. Acta Physiol 198: 223-235. CrossRef Medline

Balcita-Pedicino JJ, Sesack SR (2007) Orexin axons in the rat ventral tegmental area synapse infrequently onto dopamine and $\gamma$-aminobutyric acid neurons. J Comp Neur 503:668-684. CrossRef Medline

Barker DJ, Root DH, Zhang S, Morales M (2016) Multiplexed neurochemical signaling by neurons of the ventral tegmental area. $J$ Chem Neuroanat 73:33-42. CrossRef Medline

Barson JR, Morganstern I, Leibowitz SF (2013) Complementary roles of orexin and melanin-concentrating hormone in feeding behavior. Int J Endocrinol 2013:983964. CrossRef Medline

Benjamini Y, Hochberg Y (1995) Controlling the false discovery rate: a practical and powerful approach to multiple testing. J Royal Stat Soc, Series B 57:289-300.

Berthoud H, Münzberg H (2011) The lateral hypothalamus as integrator of metabolic and environmental needs: from electrical selfstimulation to opto-genetics. Physiol Behav 104:29-39. CrossRef Medline

Blanco-Centurion C, Liu M, Konadhode RP, Zhang X, Pelluru D, van den Pol AN, Shiromani PJ (2016) Optogenetic activation of melanin-concentrating hormone neurons increases non-rapid eye movement and rapid eye movement sleep during the night in rats. Eur J Neurosci 44:2846-2857. CrossRef Medline

Bonnavion P, Mickelsen LE, Fujita A, de Lecea L, Jackson AC (2016) Hubs and spokes of the lateral hypothalamus: cell types, circuits and behaviour. J Physiol 58:7250-7257. 
Brischoux F, Fellmann D, Risold PY (2001) Ontogenetic development of the diencephalic $\mathrm{MCH}$ neurons: a hypothalamic "MCH area" hypothesis. Eur J Neurosci 13:1733-1744. Medline

Broberger C (1999) Hypothalamic cocaine- and amphetamineregulated transcript (CART) neurons: histochemical relationship to thyrotropin-releasing hormone, melanin-concentrating hormone, orexin/hypocretin and neuropeptide Y. Brain Res 848:101-113. Medline

Brown JA, Woodworth HL, Leinninger GM (2015) To ingest or rest? Specialized roles of lateral hypothalamic area neurons in coordinating energy balance. Front Syst Neurosci 9:9. CrossRef Medline

Burdakov D, Alexopoulos H, Vincent A, Ashcroft FM (2004) Lowvoltage-activated A-current controls the firing dynamics of mouse hypothalamic orexin neurons. Eur J Neurosci 20:3281-3285. CrossRef Medline

Burdakov D, Karnani MM, Gonzalez A (2013) Lateral hypothalamus as a sensor-regulator in respiratory and metabolic control. Physiol Behav 121:117-124. CrossRef Medline

Burt J, Alberto CO, Parsons MP, Hirasawa M (2011) Local network regulation of orexin neurons in the lateral hypothalamus. Am J Physiol Regul Integr Comp Physiol 301:R572-R580. CrossRef

Cadwell CR, Palasantza A, Jiang X, Berens $P$, Deng Q, Yilmaz M, Reimer J, Shen S, Bethge M, Tolias KF, Sandberg R, Tolias AS (2015) Electrophysiological, transcriptomic and morphologic profiling of single neurons using Patch-seq. Nat Biotechnol 34:199203. CrossRef Medline

Campbell JN, Macosko EZ, Fenselau H, Pers TH, Lyubetskaya A, Tenen D, Goldman M, Verstegen AM, Resch JM, McCarroll SA, Rosen ED, Lowell BB, Tsai LT (2017) A molecular census of arcuate hypothalamus and median eminence cell types. Nat Neurosci 20:484-496. CrossRef Medline

Chee MJS, Arrigoni E, Maratos-Flier E (2015) Melanin-concentrating hormone neurons release glutamate for feedforward inhibition of the lateral septum. J Neurosci 35:3644-3651. CrossRef

Chou TC, Lee CE, Lu J, Elmquist JK, Hara J, Willie JT, Beuckmann CT, Chemelli RM, Sakurai T, Yanagisawa M, Saper CB, Scammell TE (2001) Orexin (hypocretin) neurons contain dynorphin. J Neurosci 21:RC168. Medline

Citri A, Pang ZP, Südhof TC, Wernig M, Malenka RC (2011) Comprehensive qPCR profiling of gene expression in single neuronal cells. Nat Protoc 7:1-10. CrossRef

Crocker A, España RA, Papadopoulou M, Saper CB, Faraco J, Sakurai T, Honda M, Mignot E, Scammell TE (2005) Concomitant loss of dynorphin, NARP, and orexin in narcolepsy. Neurology 65:1184-1188. CrossRef Medline

Croizier S, Amiot C, Chen X, Presse F, Nahon JL, Wu JY, Fellmann D, Risold PY (2011) Development of posterior hypothalamic neurons enlightens a switch in the prosencephalic basic plan. PLoS One 6. CrossRef

Cui H, Sohn J-W, Gautron L, Funahashi H, Williams KW, Elmquist JK, Lutter M (2012) Neuroanatomy of melanocortin-4 receptor pathway in the lateral hypothalamic area. J Comp Neur 520:41684183. CrossRef Medline

Cvetkovic V, Brischoux F, Jacquemard C, Fellmann D, Griffond B, Risold PY (2004) Characterization of subpopulations of neurons producing melanin-concentrating hormone in the rat ventral diencephalon. J Neurochem 91:911-919. CrossRef Medline

Dalal J, Roh JH, Maloney SE, Akuffo A, Shah S, Yuan H, Wamsley B, Jones WB, Strong CDG, Gray P. a, Holtzman DM, Heintz N, Dougherty JD (2013) Translational profiling of hypocretin neurons identifies candidate molecules for sleep regulation. Genes Dev 27:565-578. CrossRef

del Cid-Pellitero E, Jones BE (2012) Immunohistochemical evidence for synaptic release of GABA from melanin-concentrating hormone containing varicosities in the locus coeruleus. Neuroscience 223: 269-276. CrossRef Medline

Demarque M, Spitzer NC (2012) Neurotransmitter phenotype plasticity: an unexpected mechanism in the toolbox of network activity homeostasis. Dev Neurobiol 72:22-32. CrossRef Medline
Dennison CS, King CM, Dicken MS, Hentges ST (2016) Agedependent changes in amino acid phenotype and the role of glutamate release from hypothalamic proopiomelanocortin neurons. J Comp Neur 524:1222-1235. CrossRef Medline

Dicken MS, Hughes AR, Hentges ST (2015) Gad1 mRNA as a reliable indicator of altered GABA release from orexigenic neurons in the hypothalamus. Eur J Neurosci 42:2644-2653. CrossRef Medline

Dicken MS, Tooker RE, Hentges ST (2012) Regulation of GABA and glutamate release from proopiomelanocortin neuron terminals in intact hypothalamic networks. J Neurosci 32:4042-4048. CrossRef Medline

Dougherty JD, Maloney SE, Wozniak DF, Rieger MA, Sonnenblick L, Coppola G, Mahieu NG, Zhang J, Cai J, Patti GJ, Abrahams BS, Geschwind DH, Heintz N (2013) The disruption of Celf6, a gene identified by translational profiling of serotonergic neurons, results in autism-related behaviors. J Neurosci 33:2732-2753. CrossRef Medline

Elias CF, Lee CE, Kelly JF, Ahima RS, Kuhar M, Saper CB, Elmquist JK (2001) Characterization of CART neurons in the rat and human hypothalamus. J Comp Neur 432:1-19. Medline

Ferrari LL, Agostinelli LJ, Krashes MJ, Lowell BB, Scammell TE, Arrigoni E (2015) Dynorphin inhibits basal forebrain cholinergic neurons by pre- and post-synaptic mechanisms. J Physiol 4:1069-1085.

Fishell G, Heintz N (2013) The neuron identity problem: form meets function. Neuron 80:602-612. CrossRef Medline

Foo KS, Brismar H, Broberger C (2008) Distribution and neuropeptide coexistence of nucleobindin-2 mRNA/nesfatin-like immunoreactivity in the rat CNS. Neuroscience 156:563-579. CrossRef Medline

Fort P, Salvert D, Hanriot L, Jego S, Shimizu H, Hashimoto K, Mori M, Luppi P-H (2008) The satiety molecule nesfatin-1 is co-expressed with melanin concentrating hormone in tuberal hypothalamic neurons of the rat. Neuroscience 155:174-181. CrossRef Medline

Furutani N, Hondo M, Kageyama H, Tsujino N, Mieda M, Yanagisawa M, Shioda S, Sakurai T (2013) Neurotensin co-expressed in orexinproducing neurons in the lateral hypothalamus plays an important role in regulation of sleep/wakefulness states. PLoS One 8:e62391. CrossRef Medline

Fuzik J, Zeisel A, Máté Z, Calvigioni D, Yanagawa Y, Szabó G, Linnarsson S, Harkany T (2015) Integration of electrophysiological recordings with single-cell RNA-seq data identifies neuronal subtypes. Nat Biotechnol 34:175-183. CrossRef Medline

Gerashchenko D, Horvath TL, Xie X (2011) Direct inhibition of hypocretin/orexin neurons in the lateral hypothalamus by nociceptin/ orphanin FQ blocks stress-induced analgesia in rats. Neuropharmacology 60:543-549. CrossRef Medline

Giardino WJ, de Lecea L (2014) Hypocretin (orexin) neuromodulation of stress and reward pathways. Curr Opin Neurobiol 29:103-108. CrossRef Medline

González JA, Jensen LT, Fugger L, Burdakov D (2012) Convergent inputs from electrically and topographically distinct orexin cells to locus coeruleus and ventral tegmental area. Eur J Neurosci 35: 1426-1432. CrossRef Medline

González JA, lordanidou P, Strom M, Adamantidis A, Burdakov D (2016) Awake dynamics and brain-wide direct inputs of hypothalamic $\mathrm{MCH}$ and orexin networks. Nat Commun 7:11395. CrossRef Medline

Granger AJ, Wallace ML, Sabatini BL (2017) Multi-transmitter neurons in the mammalian central nervous system. Curr Opin Neurobiol 45:85-91. CrossRef Medline

Guan JL, Uehara K, Lu S, Wang QP, Funahashi H, Sakurai T, Yanagizawa M, Shioda S (2002) Reciprocal synaptic relationships between orexin- and melanin-concentrating hormone-containing neurons in the rat lateral hypothalamus: a novel circuit implicated in feeding regulation. Int $\mathrm{J}$ Obes Relat Metab Disord 26:15231532. CrossRef Medline

Håkansson ML, de Lecea L, Sutcliffe JG, Yanagisawa M, Meister B (1999) Leptin receptor- and STAT3-immunoreactivities in hypocre- 
tin/orexin neurones of the lateral hypothalamus. J Neuroendocrinol 11:653-663. Medline

Harthoorn LF, Sañé A, Nethe M, Van Heerikhuize JJ (2005) Multitranscriptional profiling of melanin-concentrating hormone and orexin-containing neurons. Cell Mol Neurobiol 25:1209-1223. CrossRef Medline

Hassani OK, Lee MG, Jones BE (2009) Melanin-concentrating hormone neurons discharge in a reciprocal manner to orexin neurons across the sleep-wake cycle. Proc Natl Acad Sci USA 106:24182422. CrossRef

Hassani OK, Krause MR, Mainville L, Cordova CA, Jones BE (2016) Orexin neurons respond differentially to auditory cues associated with appetitive versus aversive outcomes. J Neurosci 36:17471757. CrossRef Medline

Henny P, Brischoux F, Mainville L, Stroh T, Jones BE (2010) Immunohistochemical evidence for synaptic release of glutamate from orexin terminals in the locus coeruleus. Neuroscience 169:11501157. CrossRef Medline

Hentges ST, Nishiyama M, Overstreet LS, Stenzel-Poore M, Williams JT, Low MJ (2004) GABA release from POMC neurons. J Neurosci 24:1578-1583. CrossRef Medline

Hentges ST, Otero-Corchon V, Pennock RL, King CM, Low MJ (2009) Proopiomelanocortin expression in both GABA and glutamate neurons. J Neurosci 29:13684-13690. CrossRef Medline

Herrera C, Ponomarenko A, Korotkova T, Burdakov D, Adamantidis A (2016) Sleep \& metabolism: the multitasking ability of lateral hypothalamic inhibitory circuitries. Front Neuroendocrinol 44:2734. CrossRef Medline

Hnasko TS, Edwards RH (2012) Neurotransmitter corelease: mechanism and physiological role. Annu Rev Physiol 74:225-243. CrossRef Medline

Hof PR, Glezer II, Condé F, Flagg RA, Rubin MB, Nimchinsky EA, Vogt Weisenhorn DM (1999) Cellular distribution of the calciumbinding proteins parvalbumin, calbindin, and calretinin in the neocortex of mammals: phylogenetic and developmental patterns. J Chem Neuroanat 16:77-116. Medline

Honda M, Eriksson KS, Zhang S, Tanaka S, Lin L, Salehi A, Hesla PE, Maehlen J, Gaus SE, Yanagisawa M, Sakurai T, Taheri S, Tsuchiya $\mathrm{K}$, Honda Y, Mignot E (2009) IGFBP3 colocalizes with and regulates hypocretin (orexin). PLoS One 4:14. CrossRef

Horjales-Araujo E, Hellysaz A, Broberger C (2014) Lateral hypothalamic thyrotropin-releasing hormone neurons: distribution and relationship to histochemically defined cell populations in the rat. Neuroscience 277:87-102. CrossRef Medline

Horvath TL, Peyron C, Diano S, Ivanov A, Aston-Jones G, Kilduff TS, Van Den Pol AN (1999) Hypocretin (orexin) activation and synaptic innervation of the locus coeruleus noradrenergic system. J Comp Neur 415:145-159. Medline

Hurley SW, Johnson AK (2014) The role of the lateral hypothalamus and orexin in ingestive behavior: a model for the translation of past experience and sensed deficits into motivated behaviors. Front Syst Neurosci 8:216. CrossRef Medline

Jarvie BC, Hentges ST (2012) Expression of GABAergic and glutamatergic phenotypic markers in hypothalamic proopiomelanocortin neurons. J Comp Neur 520:3863-3876. CrossRef Medline

Jarvie BC, King CM, Hughes AR, Dicken MS, Christina S, Hentges ST (2017) Caloric restriction selectively reduces the GABAergic phenotype of mouse hypothalamic proopiomelanocortin neurons. J Physiol 595:571-582. CrossRef

Jego S, Glasgow SD, Herrera CG, Ekstrand M, Reed SJ, Boyce R, Friedman J, Burdakov D, Adamantidis AR (2013) Optogenetic identification of a rapid eye movement sleep modulatory circuit in the hypothalamus. Nat Neurosci 16:1637-1643. CrossRef Medline Jennings JH, Ung RL, Resendez SL, Stamatakis AM, Taylor JG, Huang J, Veleta K, Kantak PA, Aita M, Shilling-Scrivo K, Ramakrishnan C, Deisseroth K, Otte S, Stuber GD (2015) Visualizing hypothalamic network dynamics for appetitive and consummatory behaviors. Cell 160:516-527. CrossRef Medline
Jeong JH, Woo YJ, Chua S, Jo Y-H (2016) Single-cell gene expression analysis of cholinergic neurons in the arcuate nucleus of the hypothalamus. PLoS One 11:e0162839. CrossRef Medline

Jones BE, Hassani OK (2013) The role of Hcrt/Orx and MCH neurons in sleep-wake state regulation. Sleep 36:1769-1772. CrossRef Medline

Konadhode RR, Pelluru D, Blanco-Centurion C, Zayachkivsky A, Liu M, Uhde T, Glen WB, van den Pol AN, Mulholland PJ, Shiromani PJ (2013) Optogenetic stimulation of $\mathrm{MCH}$ neurons increases sleep. J Neurosci 33:10257-10263. CrossRef Medline

Konadhode RR, Pelluru D, Shiromani PJ (2015) Neurons containing orexin or melanin concentrating hormone reciprocally regulate wake and sleep. Front Syst Neurosci 8:1-9. CrossRef

Kong D, Vong L, Parton LE, Ye C, Tong Q, Hu X, Choi B, Brüning JC, Lowell BB (2010) Glucose stimulation of hypothalamic MCH neurons involves KATP channels, is modulated by UCP2, and regulates peripheral glucose homeostasis. Cell Metab 12:545-552. CrossRef Medline

Laque A, Zhang $\mathrm{Y}$, Gettys S, Nguyen T-A, Bui K, Morrison CD, Münzberg H (2013) Leptin receptor neurons in the mouse hypothalamus are colocalized with the neuropeptide galanin and mediate anorexigenic leptin action. Am J Physiol Endocrinol Metab 304:E999-E1011. CrossRef Medline

Lee MG (2005) Discharge of identified orexin/hypocretin neurons across the sleep-waking cycle. J Neurosci 25:6716-6720. CrossRef Medline

Leibowitz SF (2007) Overconsumption of dietary fat and alcohol: mechanisms involving lipids and hypothalamic peptides. Physiol Behav 91:513-521. CrossRef Medline

Lein ES, Hawrylycz MJ, Ao N, Ayres M, Bensinger A, Bernard A, Boe AF, Boguski MS, Brockway KS, Byrnes EJ, Chen L, Chen L, Chen TM, Chin MC, Chong J, Crook BE, Czaplinska A, Dang CN, Datta S, Dee NR, et al. (2007) Genome-wide atlas of gene expression in the adult mouse brain. Nature 445:168-176. CrossRef Medline

Leinninger GM, Jo Y-H, Leshan RL, Louis GW, Yang H, Barrera JG, Wilson H, Opland DM, Faouzi MA, Gong Y, Jones JC, Rhodes CJ, Chua S, Diano S, Horvath TL, Seeley RJ, Becker JB, Münzberg H, Myers MG (2009) Leptin acts via leptin receptor-expressing lateral hypothalamic neurons to modulate the mesolimbic dopamine system and suppress feeding. Cell Metab 10:89-98. CrossRef Medline

Leinninger GM, Opland DM, Jo Y-H, Faouzi M, Christensen L, Cappellucci LA, Rhodes CJ, Gnegy ME, Becker JB, Pothos EN, Seasholtz AF, Thompson RC, Myers MG (2011) Leptin action via neurotensin neurons controls orexin, the mesolimbic dopamine system and energy balance. Cell Metab 14:313-323. CrossRef Medline

Li Y, van den Pol AN (2006) Differential target-dependent actions of coexpressed inhibitory dynorphin and excitatory hypocretin/orexin neuropeptides. J Neurosci 26:13037-13047. CrossRef Medline

Liu C, Lee S, Elmquist JK (2014) Circuits controlling energy balance and mood: inherently intertwined or just complicated intersections? Cell Metab 19:902-909. CrossRef Medline

Liu J, Merkle FT, Gandhi AV, Gagnon JA, Woods IG, Chiu CN, Shimogori T, Schier AF, Prober DA (2015) Evolutionarily conserved regulation of hypocretin neuron specification by Lhx9. Development 142:1113-1124. CrossRef Medline

Madisen L, Zwingman TA, Sunkin SM, On SW, Zariwala HA, Gu H, $\mathrm{Ng}$ LL, Palmiter RD, Hawrylycz MJ, Jones AR, Lein ES, Zeng H (2010) A robust and high-throughput Cre reporting and characterization system for the whole mouse brain. Nat Neurosci 13:133140. CrossRef Medline

Mahler SV, Moorman DE, Smith RJ, James MH, Aston-Jones G (2014) Motivational activation: a unifying hypothesis of orexin/ hypocretin function. Nat Neurosci 17:1298-1303. CrossRef Medline

Maloney SE, Khangura E, Dougherty JD (2016) The RNA-binding protein Celf6 is highly expressed in diencephalic nuclei and neuromodulatory cell populations of the mouse brain. Brain Struct Funct 221:1809-1831. CrossRef Medline 
Maolood N, Meister B (2010) Nociceptin/orphanin FQ peptide in hypothalamic neurones associated with the control of feeding behaviour. J Neuroendocrinol 22:75-82. CrossRef Medline

Mészár Z, Girard F, Saper CB, Celio MR (2012) The lateral hypothalamic parvalbumin-immunoreactive (PV1) nucleus in rodents. J Comp Neur 520:798-815. CrossRef Medline

Mileykovskiy BY, Kiyashchenko LI, Siegel JM (2005) Behavioral correlates of activity in identified hypocretin/orexin neurons. Neuron 46:787-798. CrossRef Medline

Monti JM, Torterolo P, Lagos P (2013) Melanin-concentrating hormone control of sleep-wake behavior. Sleep Med Rev 17:293-298. CrossRef Medline

Münster-Wandowski A, Gómez-Lira G, Gutiérrez R (2013) Mixed neurotransmission in the hippocampal mossy fibers. Front Cell Neurosci 7:210CrossRef Medline

Muschamp JW, Hollander JA, Thompson JL, Voren G, Hassinger LC, Onvani S, Kamenecka TM, Borgland SL, Kenny PJ, Carlezon WA (2014) Hypocretin (orexin) facilitates reward by attenuating the antireward effects of its cotransmitter dynorphin in ventral tegmental area. Proc Natl Acad Sci USA 111:E1648-E1655. CrossRef Medline

Nelson SB, Sugino K, Hempel CM (2006) The problem of neuronal cell types: a physiological genomics approach. Trends Neurosci 29:339-345. CrossRef Medline

Okaty BW, Sugino K, Nelson SB (2011) A quantitative comparison of cell-type-specific microarray gene expression profiling methods in the mouse brain. PLoS One 6:1-10. CrossRef

Paxinos G, Franklin K (2012) Paxinos and Franklin's the mouse brain in stereotaxic coordinates, Ed 4. New York: Academic Press.

Pissios P, Bradley RL, Maratos-Flier E (2006) Expanding the scales: the multiple roles of $\mathrm{MCH}$ in regulating energy balance and other biological functions. Endocr Rev 27:606-620. CrossRef Medline

Raj A, van Oudenaarden A (2008) Nature, nurture, or chance: stochastic gene expression and its consequences. Cell 135:216-226. CrossRef Medline

Reti IM, Reddy R, Worley PF, Baraban JM (2002) Selective expression of Narp, a secreted neuronal pentraxin, in orexin neurons. $J$ Neurochem 82:1561-1565. Medline

Romanov RA, Zeisel A, Bakker J, Girach F, Hellysaz A, Tomer R, Alpár A, Mulder J, Clotman F, Keimpema E, Hsueh B, Crow AK, Martens H, Schwindling C, Calvigioni D, Bains JS, Máté Z, Szabó G, Yanagawa Y, Zhang MD, et al. (2017) Molecular interrogation of hypothalamic organization reveals distinct dopamine neuronal subtypes. Nat Neurosci 20:176-188. CrossRef Medline

Root DH, Mejias-Aponte CA, Zhang S, Wang HL, Hoffman AF, Lupica CR, Morales M (2014) Single rodent mesohabenular axons release glutamate and GABA. Nat Neurosci 17:1543-1551. CrossRef Medline

Rosin DL, Weston MC, Sevigny CP, Stornetta RL, Guyenet PG (2003) Hypothalamic orexin (hypocretin) neurons express vesicular glutamate transporters VGLUT1 or VGLUT2. J Comp Neur 465:593603. CrossRef Medline

Sakurai T (2014) The role of orexin in motivated behaviours. Nat Rev Neurosci 15:719-731. CrossRef Medline

Sakurai T, Moriguchi T, Furuya K, Kajiwara N, Nakamura T, Yanagisawa M, Goto K (1999) Structure and function of human preproorexin gene. J Biol Chem 274:17771-17776. Medline

Sapin E, Bérod A, Léger L, Herman PA, Luppi PH, Peyron C (2010) A very large number of GABAergic neurons are activated in the tuberal hypothalamus during paradoxical (REM) sleep hypersomnia. PLoS One 5:e11766. CrossRef Medline

Schöne C, Burdakov D (2012) Glutamate and GABA as rapid effectors of hypothalamic "peptidergic" neurons. Front Behav Neurosci 6:81CrossRef Medline

Schöne C, Venner A, Knowles D, Karnani MM, Burdakov D (2011) Dichotomous cellular properties of mouse orexin/hypocretin neurons. J Physiol 589:2767-2779. CrossRef Medline

Schöne C, Cao ZFH, Apergis-Schoute J, Adamantidis A, Sakurai T, Burdakov D (2012) Optogenetic probing of fast glutamatergic transmission from hypocretin/orexin to histamine neurons in situ. J Neurosci 32:12437-12443. CrossRef

Schöne C, Apergis-Schoute J, Sakurai T, Adamantidis A, Burdakov D (2014) Coreleased orexin and glutamate evoke nonredundant spike outputs and computations in histamine neurons. Cell Rep 7:697-704. CrossRef Medline

Seal RP, Edwards RH (2006) Functional implications of neurotransmitter co-release: glutamate and GABA share the load. Curr Opin Pharmacol 6:114-119. CrossRef Medline

Shabel SJ, Proulx CD, Piriz J, Malinow R (2014) GABA/glutamate co-release controls habenula output and is modified by antidepressant treatment. Science 345:1494-1498. CrossRef Medline

Shimogori T, Lee DA, Miranda-Angulo A, Yang Y, Wang H, Jiang L, Yoshida AC, Kataoka A, Mashiko H, Avetisyan M, Qi L, Qian J, Blackshaw S (2010) A genomic atlas of mouse hypothalamic development. Nat Neurosci 13:767-775. CrossRef Medline

Sokolowski K, Esumi S, Hirata T, Kamal Y, Tran T, Lam A, Oboti L, Brighthaupt S-C, Zaghlula M, Martinez J, Ghimbovschi S, Knoblach S, Pierani A, Tamamaki N, Shah NM, Jones KS, Corbin JG (2015) Specification of select hypothalamic circuits and innate behaviors by the embryonic patterning gene Dbx1. Neuron 86: 403-416. CrossRef Medline

Spiegelhalder K, Regen W, Nanovska S, Baglioni C, Riemann D (2013) Comorbid sleep disorders in neuropsychiatric disorders across the life cycle. Curr Psychiatry Rep 15. CrossRef

Sternson SM (2013) Hypothalamic survival circuits: blueprints for purposive behaviors. Neuron 77:810-824. CrossRef Medline

Stuber GD, Wise RA (2016) Lateral hypothalamic circuits for feeding and reward. Nat Neurosci 19:198-205. CrossRef Medline

Takahashi K, Lin JS, Sakai K (2008) Neuronal activity of orexin and non-orexin waking-active neurons during wake-sleep states in the mouse. Neuroscience 153:860-870. CrossRef Medline

Tasic B, Menon V, Nguyen TN, Kim TK, Jarsky T, Yao Z, Levi B, Gray LT, Sorensen SA, Dolbeare T, Bertagnolli D, Goldy J, Shapovalova N, Parry S, Lee C, Smith K, Bernard A, Madisen L, Sunkin SM, Hawrylycz M, et al. (2016) Adult mouse cortical cell taxonomy revealed by single cell transcriptomics. Nat Neurosci 19:335-346. CrossRef

Torrealba F, Yanagisawa M, Saper CB (2003) Colocalization of orexin a and glutamate immunoreactivity in axon terminals in the tuberomammillary nucleus in rats. Neuroscience 119:1033-1044. Medline

Tritsch NX, Ding JB, Sabatini BL (2012) Dopaminergic neurons inhibit striatal output through non-canonical release of GABA. Nature 490:262-266. CrossRef Medline

Tritsch NX, Granger AJ, Sabatini BL (2016) Mechanisms and functions of GABA co-release. Nat Rev Neurosci 17:139-145. CrossRef Medline

Tsunematsu T, Ueno T, Tabuchi S, Inutsuka A, Tanaka KF, Hasuwa H, Kilduff TS, Terao A, Yamanaka A (2014) Optogenetic manipulation of activity and temporally controlled cell-specific ablation reveal a role for $\mathrm{MCH}$ neurons in sleep/wake regulation. J Neurosci 34:6896-6909. CrossRef Medline

van den Pol AN (2012) Neuropeptide transmission in brain circuits. Neuron 76:98-115. CrossRef Medline

Vetrivelan R, Kong D, Ferrari LL, Arrigoni E, Madara JC, Bandaru SS, Lowell BB, Lu J, Saper CB (2016) Melanin-concentrating hormone neurons specifically promote rapid eye movement sleep in mice. Neuroscience 336:102-113. CrossRef Medline

Volgin DV, Swan J, Kubin L (2004) Single-cell RT-PCR gene expression profiling of acutely dissociated and immunocytochemically identified central neurons. J Neurosci Methods 136:229-236. CrossRef Medline

Vong L, Ye C, Yang Z, Choi B, Chua S, Lowell BB (2011) Leptin action on GABAergic neurons prevents obesity and reduces inhibitory tone to POMC neurons. Neuron 71:142-154. CrossRef Medline

Vrang N, Larsen PJ, Clausen JT, Kristensen P (1999) Neurochemical characterization of hypothalamic cocaine- amphetamine-regulated transcript neurons. J Neurosci 19:RC5. 
Wallace ML, Saunders A, Huang KW, Philson AC, Goldman M, Macosko EZ, McCarroll SA, Sabatini BL (2017) Genetically distinct parallel pathways in the entopeduncular nucleus for limbic and sensorimotor output of the basal ganglia. Neuron 94:138-152. CrossRef Medline

Wang F, Flanagan J, Su N, Wang LC, Bui S, Nielson A, Wu X, Vo HT, Ma XJ, Luo Y (2012) RNAscope: a novel in situ RNA analysis platform for formalin-fixed, paraffin-embedded tissues. J Mol Diagnostics 14:22-29. CrossRef Medline

Ward JH (1963) Hierarchical grouping to optimize an objective function. J Am Stat Assoc 58:236-244. CrossRef

Wu Y, Wang W, Díez-Sampedro A, Richerson GB (2007) Nonvesicular inhibitory neurotransmission via reversal of the GABA transporter GAT-1. Neuron 56:851-865. CrossRef Medline

Wulff K, Gatti S, Wettstein JG, Foster RG (2010) Sleep and circadian rhythm disruption in psychiatric and neurodegenerative disease. Nat Rev Neurosci 11:589-599. CrossRef Medline
Yamanaka A, Beuckmann CT, Willie JT, Hara J, Tsujino N, Mieda M, Tominaga M, Yagami KI, Sugiyama F, Goto K, Yanagisawa M, Sakurai T (2003) Hypothalamic orexin neurons regulate arousal according to energy balance in mice. Neuron 38:701-713. Medline

Yaron JR, Ziegler CP, Tran TH, Glenn HL, Meldrum DR (2014) A convenient, optimized pipeline for isolation, fluorescence microscopy and molecular analysis of live single cells. Biol Proced Online 16:9. CrossRef Medline

Yelin-Bekerman L, Elbaz I, Diber A, Dahary D, Gibbs-Bar L, Alon S, Lerer-Goldshtein T, Appelbaum L (2015) Hypocretin neuronspecific transcriptome profiling identifies the sleep modulator Kcnh4a. Elife 4:e08638. CrossRef Medline

Yoo JH, Zell V, Gutierrez-Reed N, Wu J, Ressler R, Shenasa MA, Johnson AB, Fife KH, Faget L, Hnasko TS (2016) Ventral tegmental area glutamate neurons co-release GABA and promote positive reinforcement. Nat Commun 7:13697. CrossRef Medline 